\title{
DESIGN CONSIDERATIONS OF WOMEN'S HEALTH HOSPITALS OF (MUKALLA CITY IN YEMEN
}

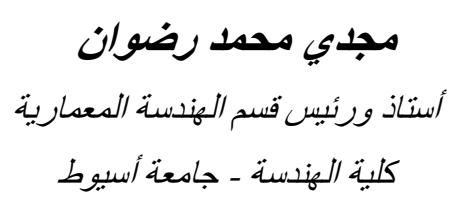

$$
\begin{aligned}
& \text { معدوح علي يوسف، } \\
& \text { مدرس بقسم المندسة المعدارية } \\
& \text { كلية العندسة - جامعة أسيوط }
\end{aligned}
$$$$
\text { وفاء عبدالله بلبعلا، }
$$

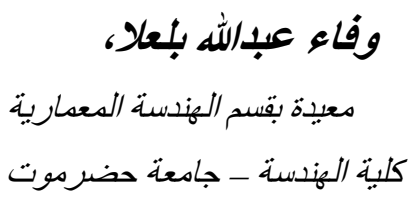

(Received July 6, 2009 Accepted August 11, 2009).

Hospitals are important buildings for the health of the individuals. They have considerations and criteria appropriate to the nature of the task they perform and the kind of users in order to fulfill their aims of providing the necessary treatment for patients, education and training of doctors in various disciplines.

The research aim is to identify the reality of women's health hospital buildings in the city of Mukalla in Yemen for the detection of existing problems, and the extent of user satisfaction about hospital services which depending on the field study about the hospital (survey and questionnaire) to identify the problems and provide treatments and solutions.

To achieve the goal of the research through the analytical approach, it has begin by giving a background on the theoretical considerations for the design of women's health hospitals to take measures of the effectiveness of the procedures for the analysis and to provide solutions and recommendations to improve the quality of hospital services.

\section{الاعتبار ات التصميمية لمستثفيات صحة المرأة بمدينة المكلا باليمن}

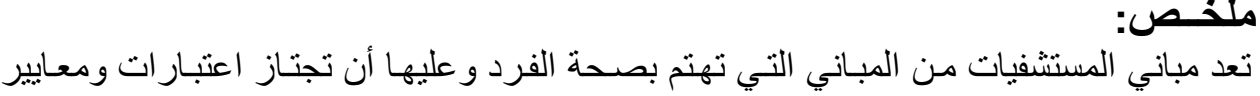

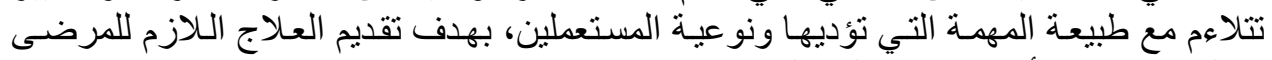
وتعليم وتدريب الأطباء في مختلف التخدة التخصصات.

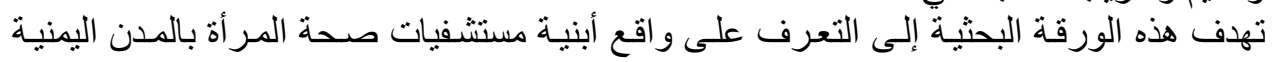

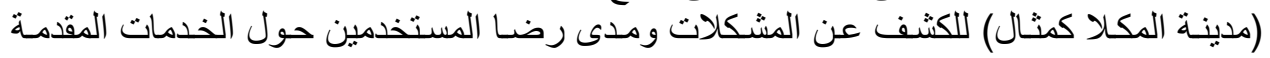

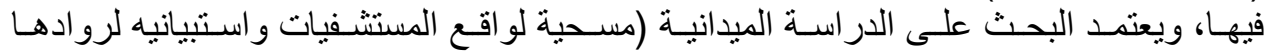

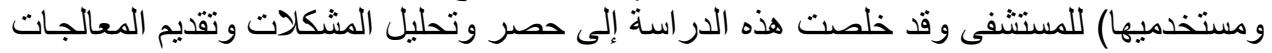
وتوجهات الحلول المناسبة للو اقع.

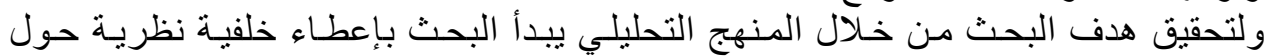

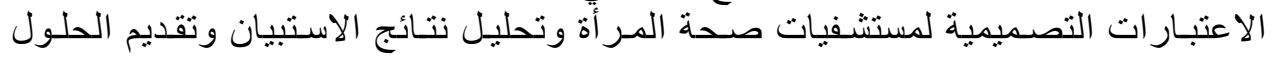
و التوصيات التي تكفل تحسين مستوى الخدمات بالمستشفى. 
تؤثر الو لادة بمساعدة طبية تأثنير إ إيجابياً على كل من الأم والمولود لاستخدام الإجر اءات الطبية

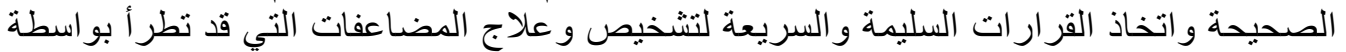

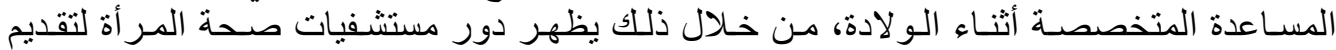

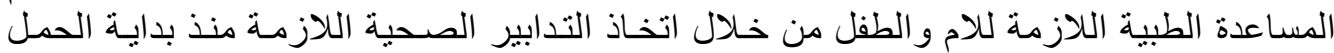

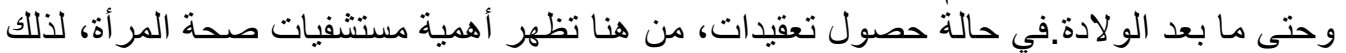

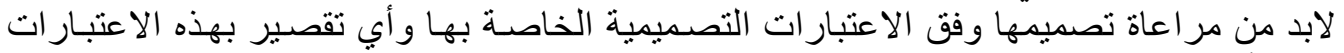

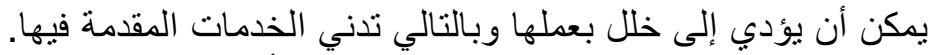

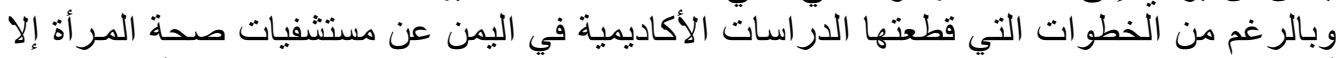

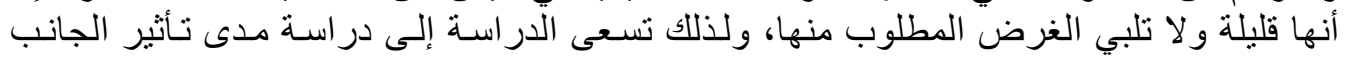
المعماري على الخدمات المقدمة في هذه المستشفيات.

\section{إشكاليـة الدراسة:}

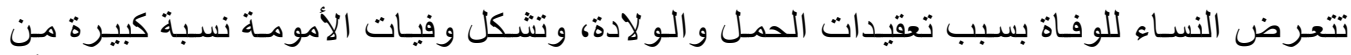

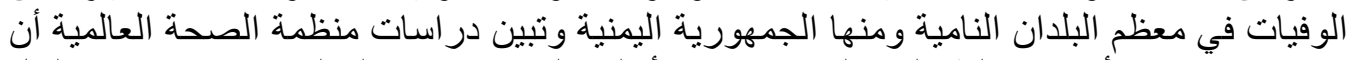

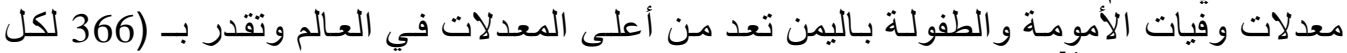

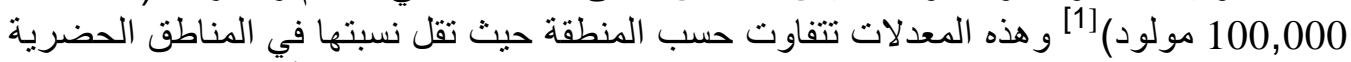
وترتفع في المناطق الريفية بسبب صعوبة الوصول للخدمات، ولهذه المشكلة أبعاد مختلفة اجتماعية

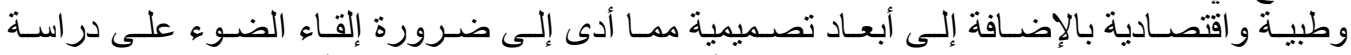

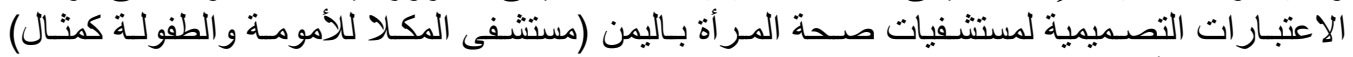

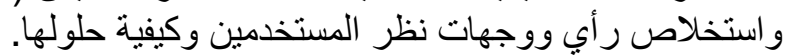

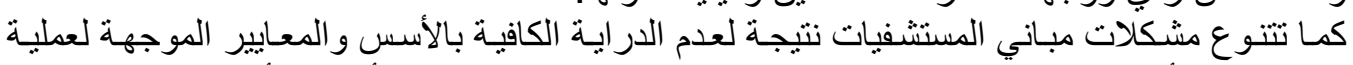

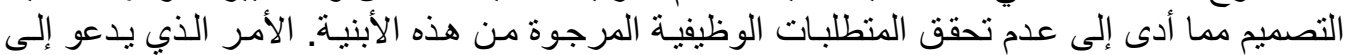

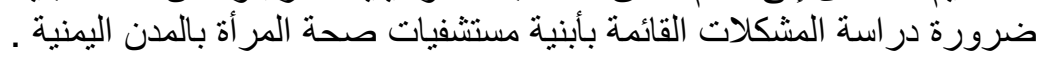

\section{الإدف من الاراسة:}

يهدف البحث إلى دراسة مدى تأثير الجانب المعماري على الخدمات المقدمة في مسنشفيات صحة المر أة

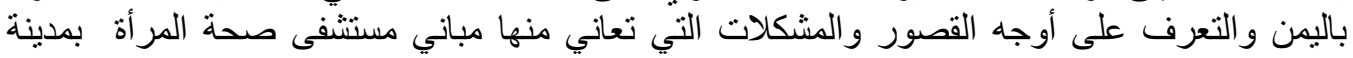
المكلا باليمن بغية الخروج بتوجهات آلـو حلول تعمل على رفع كفاءة خدماتها.

\section{منهجية الدراسة: مئية}

إن جمع المعلومات اللازمة لهذه الدر اسة يعتمد على جمع قاعدة البيانات النظرية للمستشفيات ودر اسة

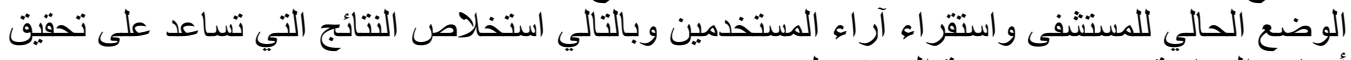

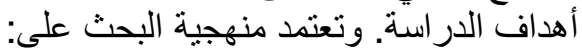

المر أةهج الوصفي: ويشمل المدخل النظري للمستشفيات و قاعدة البيانات الأساسية لمستشفيات صحة

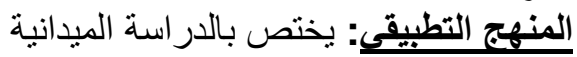

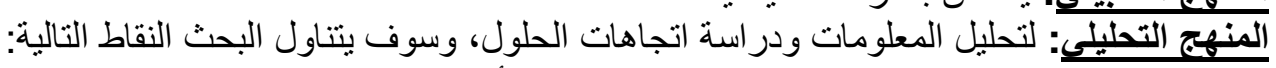
1: الاعتبار ات التصميمية لمستشفيات صحة المردية أة. 


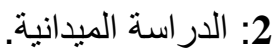

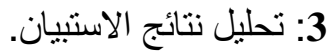

4: 3: البدائل و المقترحات لأن لحل المشكلات القائمة.

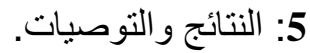

\section{1- الاعتبارات التصميمية لمستثفيات صحة المرأة:}

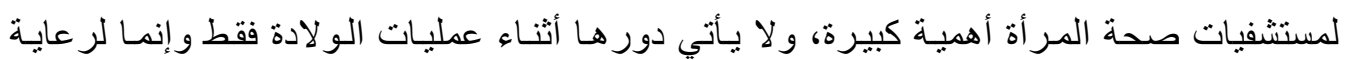

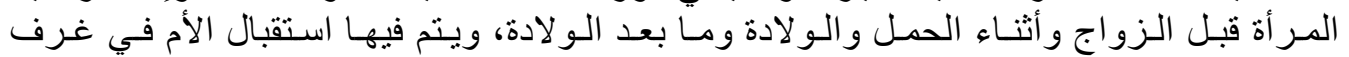

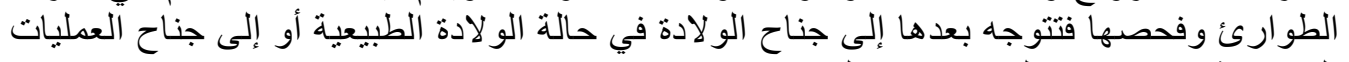
القيصرية إذا كانت هناك تعقيدات بالت بالو لادة.

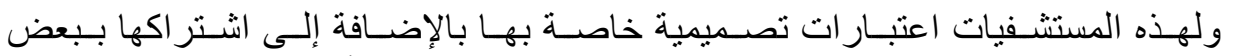

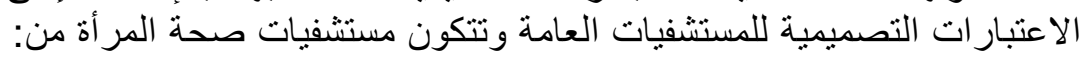

\section{أولأ: وحدة التشخيص وارت العلاج:}

و هي الوحدة المختصة بمتابعة الأم الحامل وحتى و لادتها من خـلال متابعـة حالـة الحمل و القيام

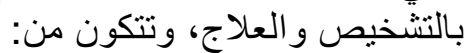

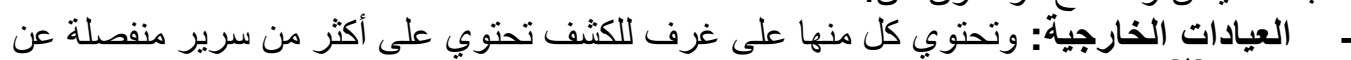

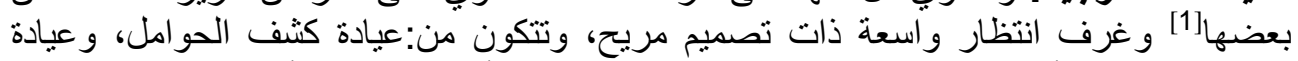

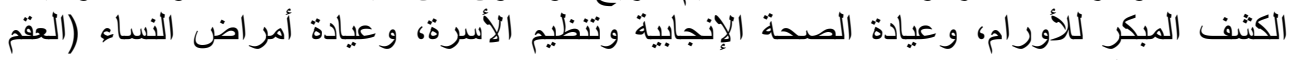

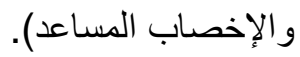
الطوارئ والاستقبال: تقوم وحدة الطوارئ باستقبال حالات الو لادة الطارئة في غرفة الاستقبال ثم ثمثئ

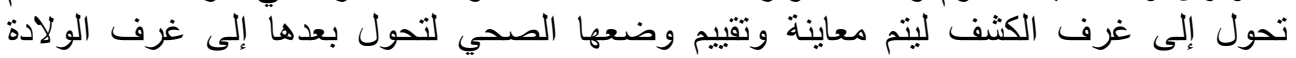
الطبيعية وإذا كانت هناك تعقيدات في الو لادة فتحول إلى جناح التهاح التعليات القيصرية.

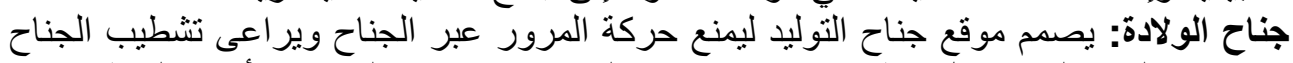

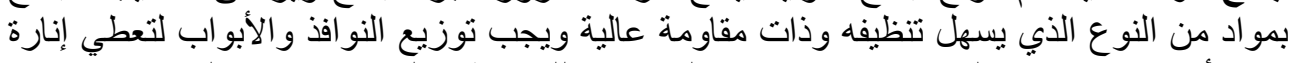

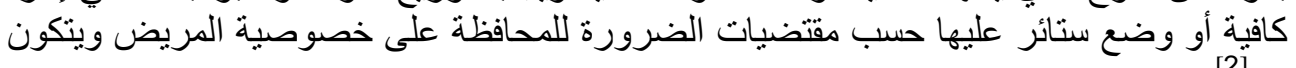

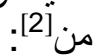

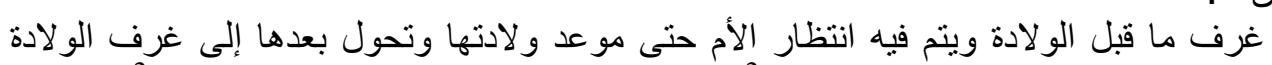

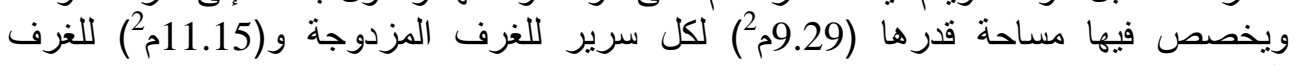

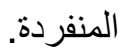
غرف الو لادة الطبيعية: وهي الغرف التي تتم فيها الولادات الطبيعية في حدود مساحة لا تقل عن (33.45 . غرف ما بعد الولادة: تقع في جناح مستقل أو كجزء من جناح الولادة بمساحة لا نقل عن [3] (327.87) جناح العمليات: يفضل أن يكون الموقع المقترح لجناح العطليات على علاقة مباشرة بجناح التوليد

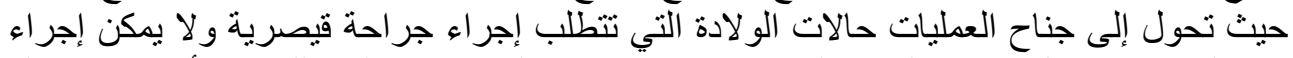

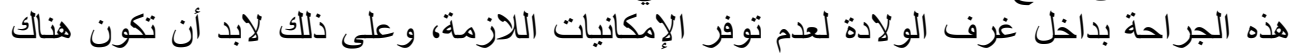


وسيلة اتصال سهلة وسريعة بين جناحي الولادة والعمليات وتكون أما أفقية (في حالة المستشفيات

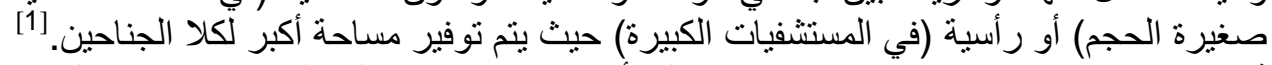
قسم المختبرات: تتكون مختبرات صحة المرأة من مختبرات بنك الدام ومختبرات الوات الوراثة،

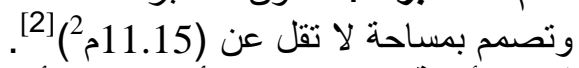
- قسم الأشعة: يعتبر قسم الأشعة من الأقسام المهمة بالمستشفى ويرتبط عبر مدخل مبانشر بقسم

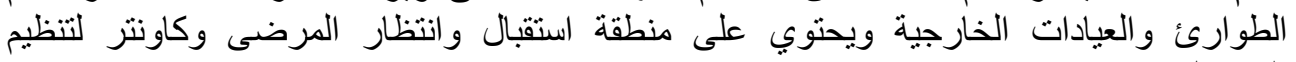

الوصول.

\section{ثانياً: وحدة الإقامة لرعاية الأم:}

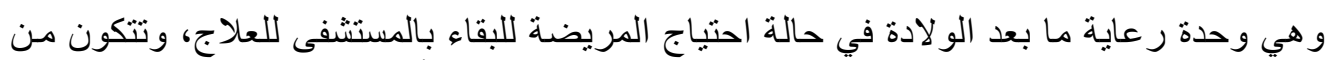

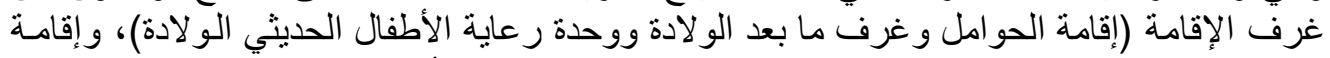

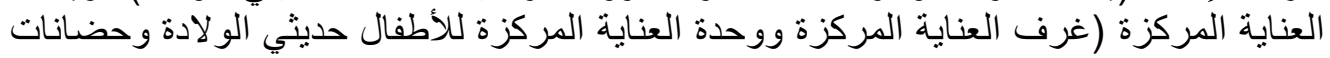

\section{ثالثاً: وحدة الخدمات العامة:}

و وتتكون من الخدمات الإدارية والاجتماعية و المعاونة و الفنية بالمستشفى.المتمنلة في المكاتب الإداريـة

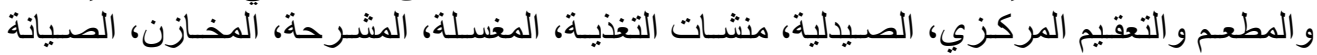

$$
\text { و غير ها. }
$$

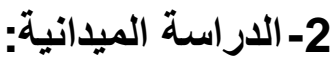

تعتبر الدراسة الميدانية هي عملية فحص لمشكلة ما وتحليلها للوصول إلى حلول من خلال المسح

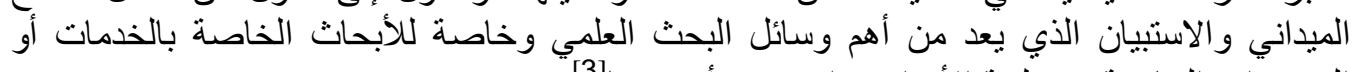

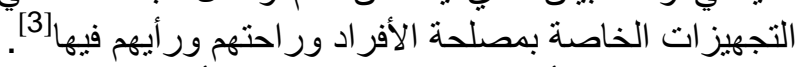

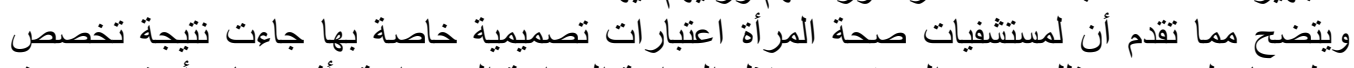

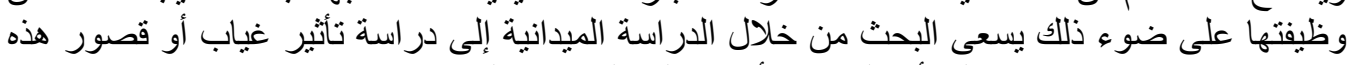

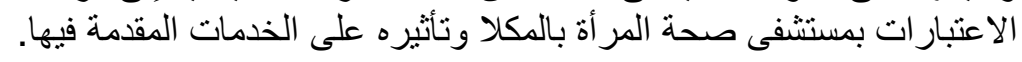

$$
\text { 1-2 - 2 - المسح الميداني: }
$$

يعتبر المسح الميداني الأسلوب الأكثر واقعية للكثف عن المشكلات الموجودة بالمستشفى وقد تم إتباع

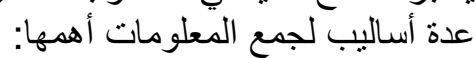

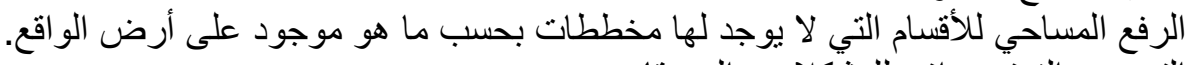

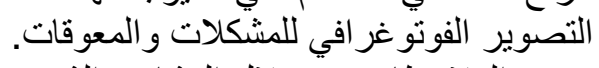

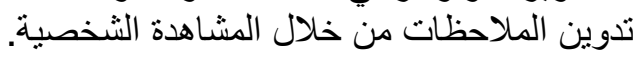

إجر اء مقابلات مع المرضى والأطباء و الإداريين بالمستشفى للتعرف على على المشـاكل التي تصـادفهم أثتاء 


\section{2-2-2 البحث الميداني (الاستبيان):}

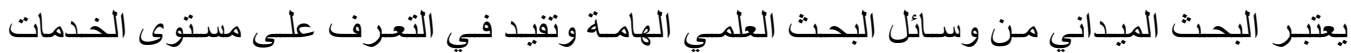

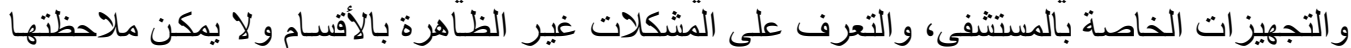

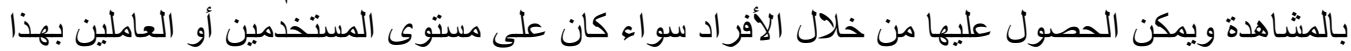

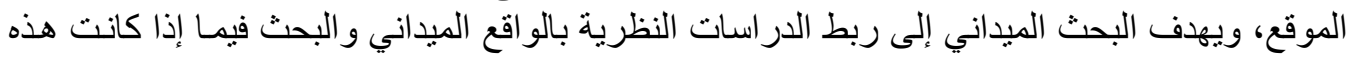

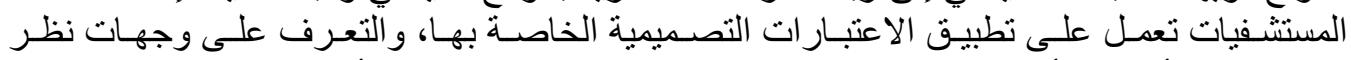

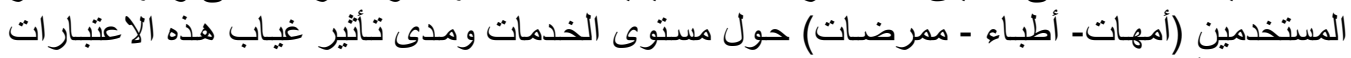
على كفاءة أداءها.

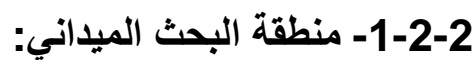

تعتبر مدينة المكلا عاصمة محافظة حضرموت منطية اكبر المحافظات مساحة في الجمهورية اليمنية، ويبلغ

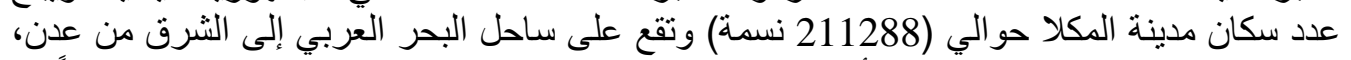

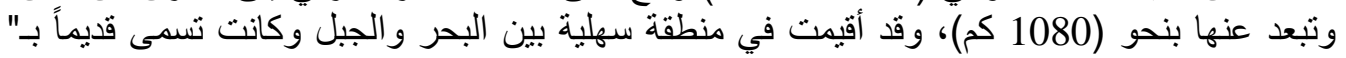

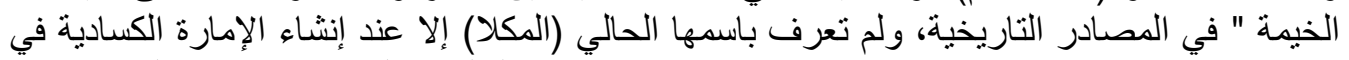

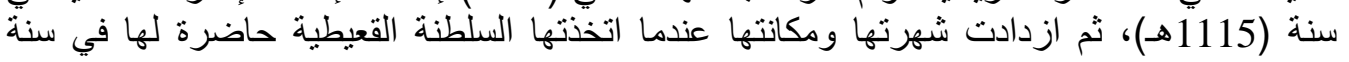

و أقام بها السلطان و اتخذها مقر أ للحكم، وتمتاز المكلا بطابعها المعماري المميز بروعة مآذنها ومبانيها

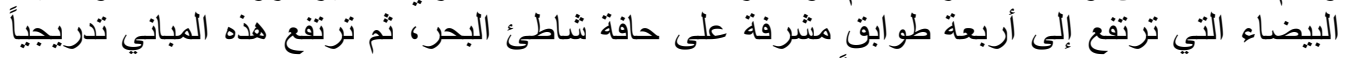

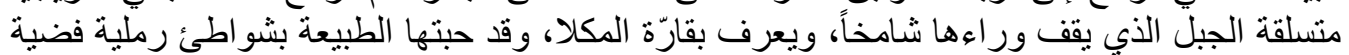

ناعمة

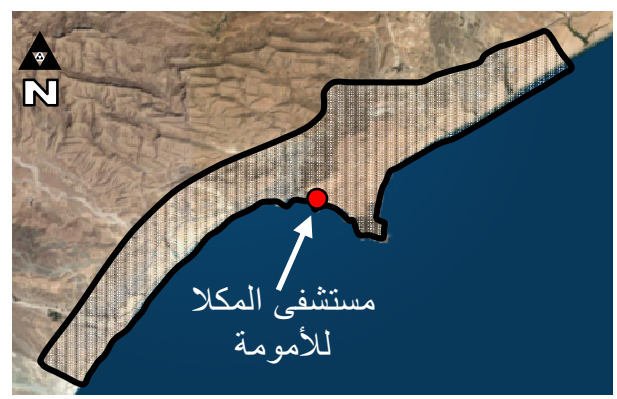

شكل(2): خارطة مدينة المكلا موضح عليها موقع المستشفى.

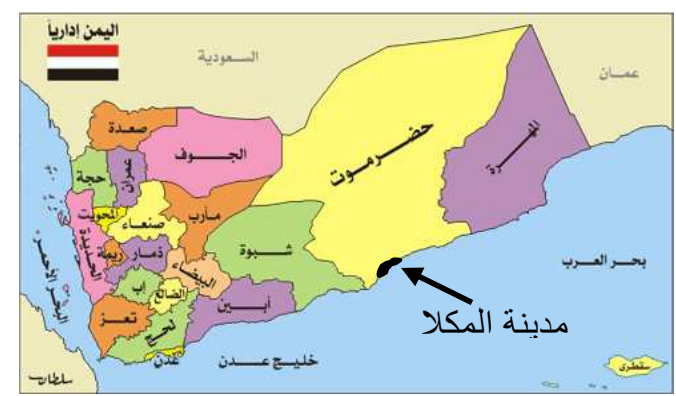

شكل(1): خارطة الجمهورية اليمنية موضح عليها موقع مدينة المكلا.

ويمكن تقسيم مدينة المكلا إلى ثلاث مناطق:

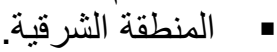
ه المنطقة الغربية.

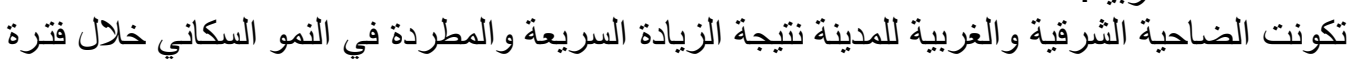

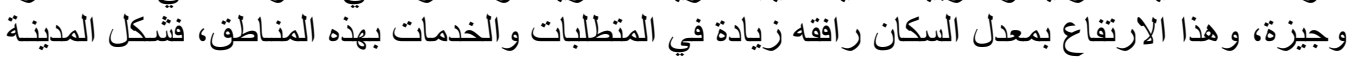

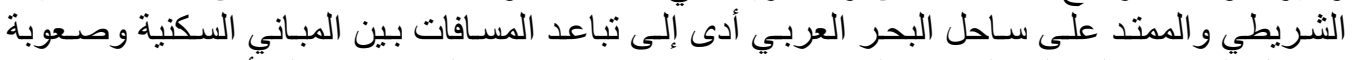

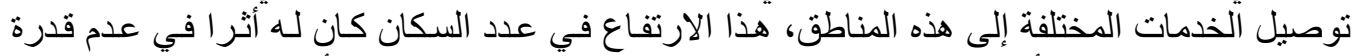

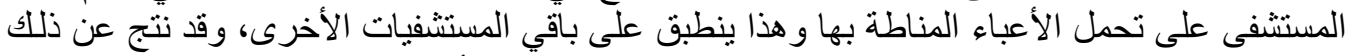

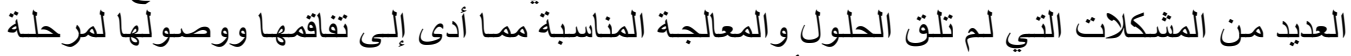

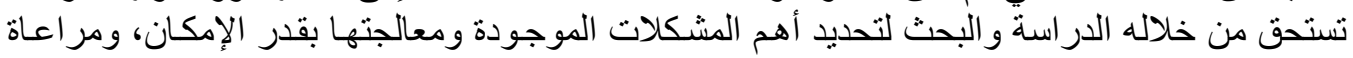




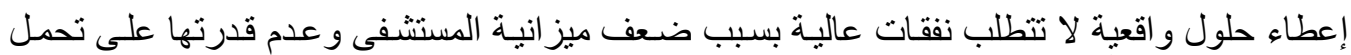

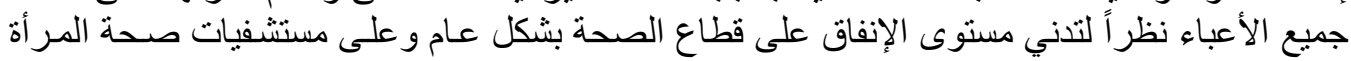
بشكل خاص.

يعتبر مناخ محافظة حضرموت مداري حار صيفا بشكل عام وفي المناطق الساحلية تكون درجة

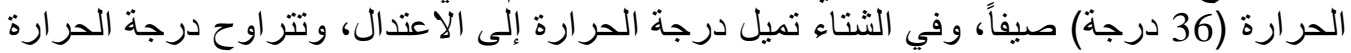

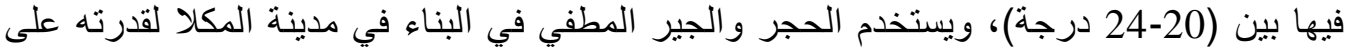
تحمل درجات الرطوبة العالية.

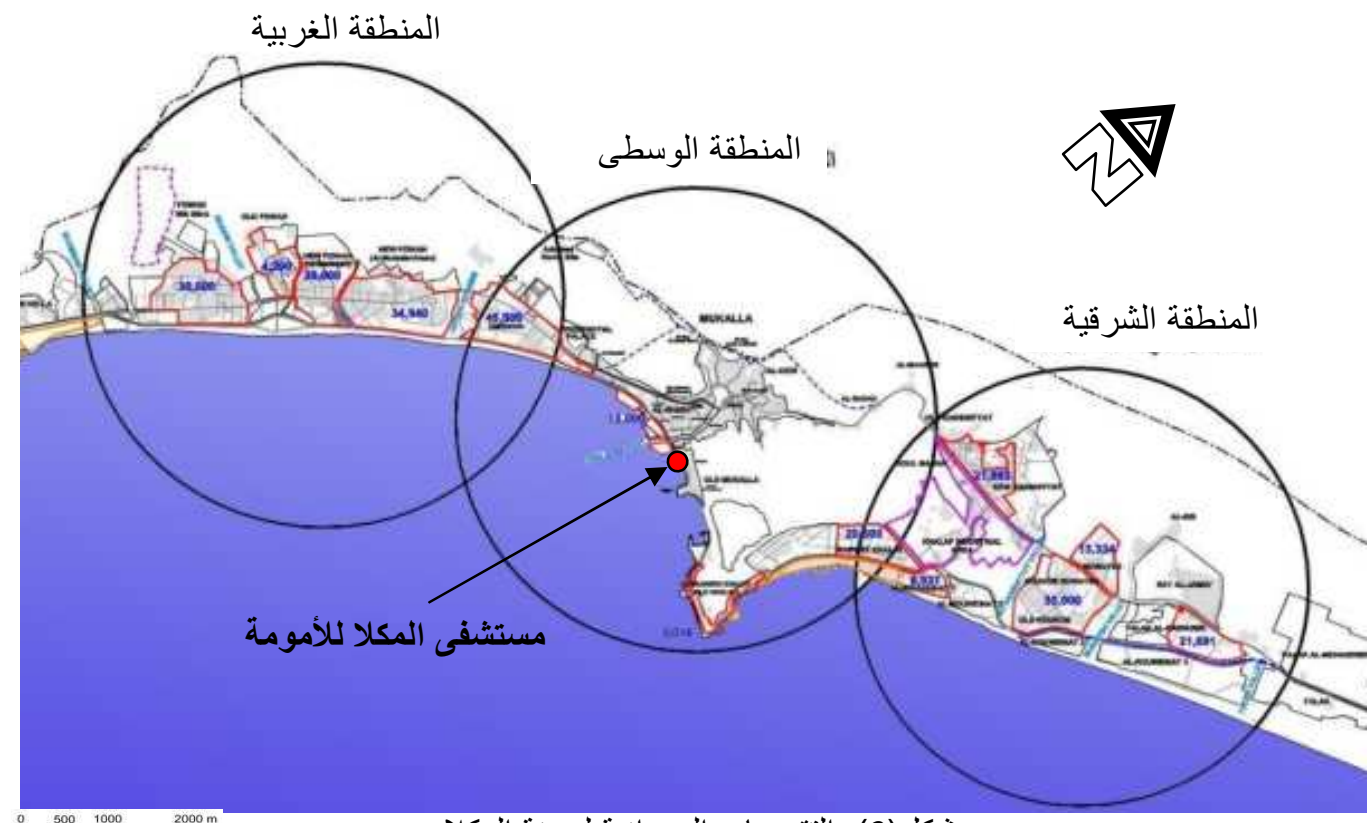

شكل(3): التقسيمات العمر انية لمدينة المكلا. .

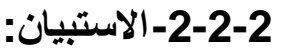

يعتبر الاستبيان من وسائل البحث المهمة للحصول على المعلومات المعل وخصوصـا التي لا يمكن ملاحظتها

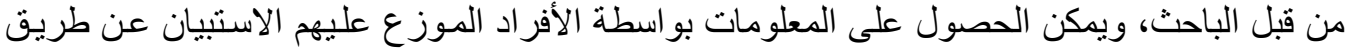

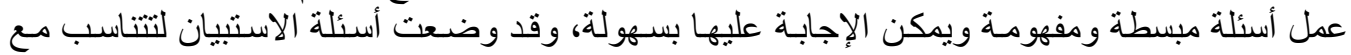

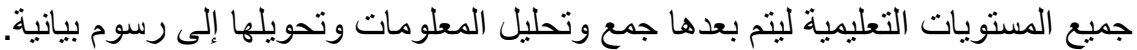
أ- الكهف من الاستبيان:

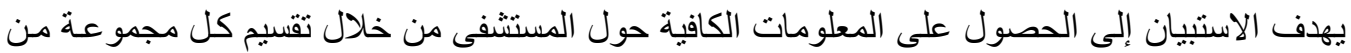

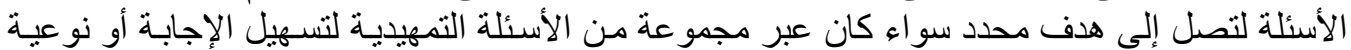

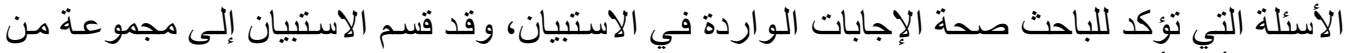

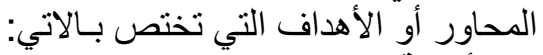

• أهمية المستشفى: و التي يسنتف منها مدى وعي الأمهات لأهمية الولادة بمستشفيات صحة المر أة

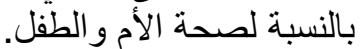

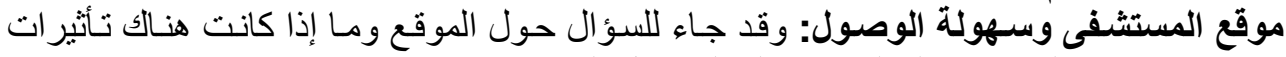

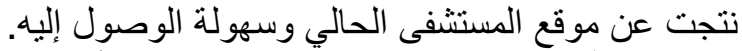
الخصوصية: لمعرفة مقدار توفير الخصوية الخصوصية للأمهات.

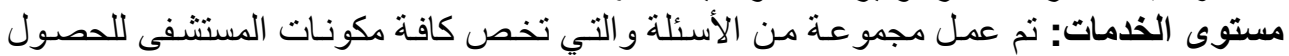

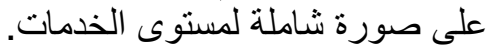


مكونات المستثفى: ويقصد بها الأقسام وما تحتويه من أثاث و أجهزة طبية.

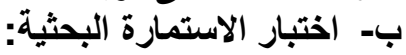

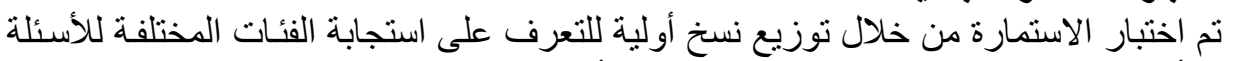

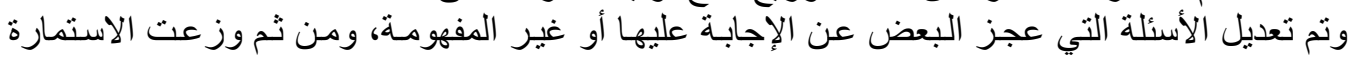

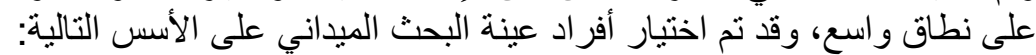

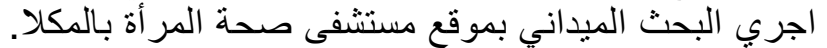

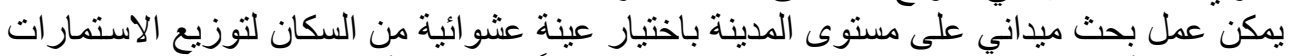

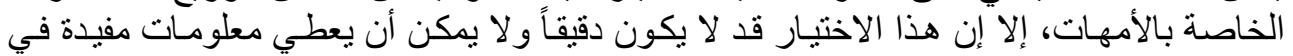

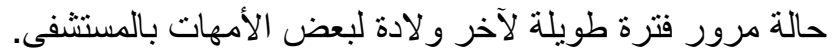

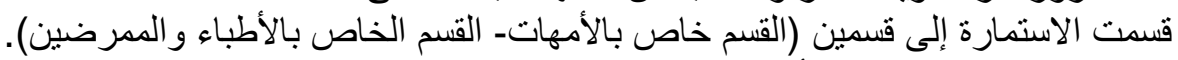

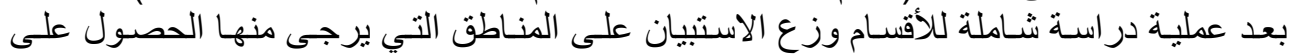

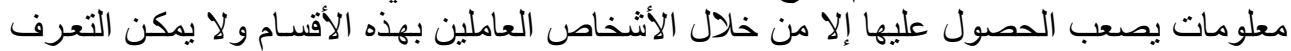
عليها بالمشاهدة الثخصية للباحثة. تحليل نتائج الاستبيان:

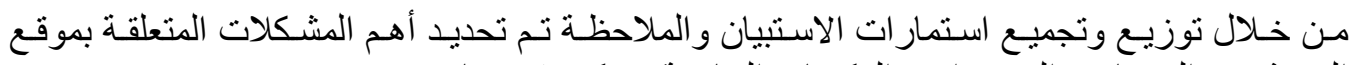

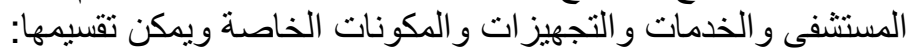

\section{-1-3- من وجهة نظر الأمهات:}

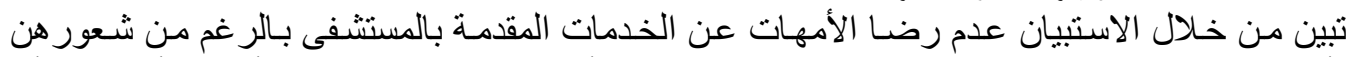

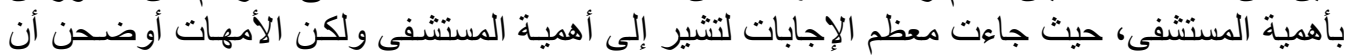

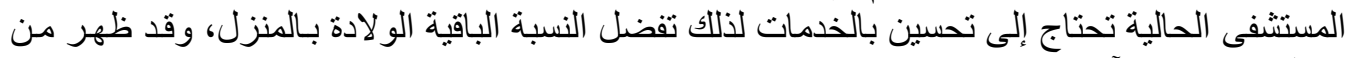

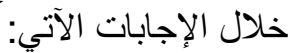

بالر غم من سهولة الوصول إلى موقع المستشفى وهو يقع بمنطقة وسطية للمدينة ولكن كان لإللك

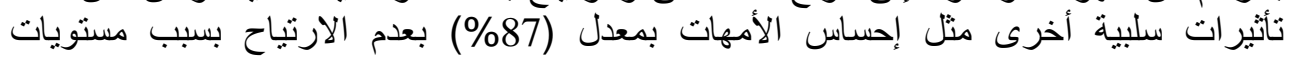

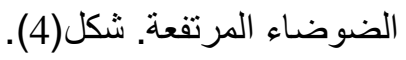

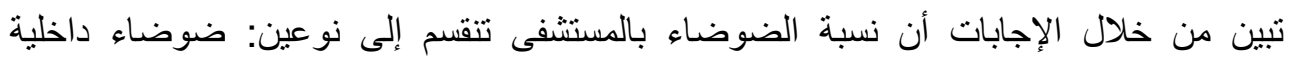

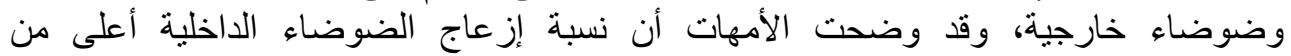

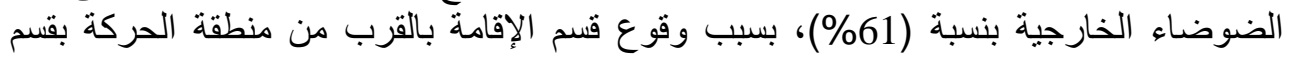

التشخيص و العلاج. شكل(5) النئة
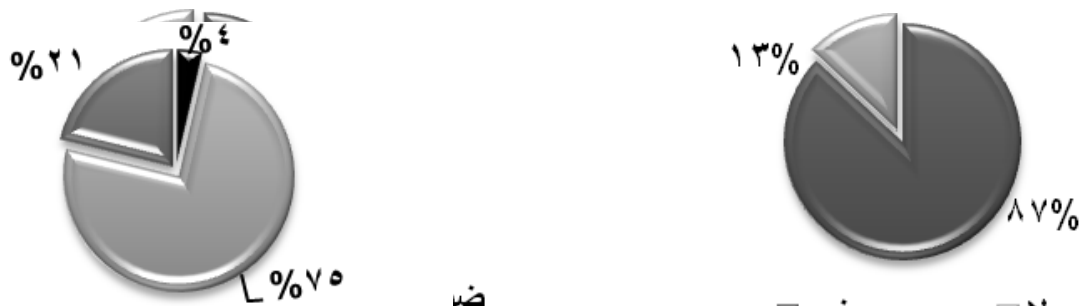

ض

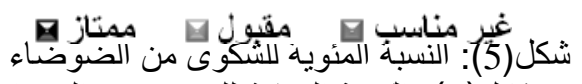

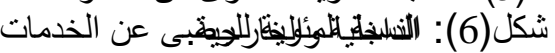

ن

هاب

شكل(4): النسبة المئوية للشعور بالضوضاء المرتفعة من قبل الامهات.

الخدمات المقدمة بالمستشفى لا تلبي حاجات 
المستخدمين ولا تلقى رضا الأمهات فكانت الإجابة بان نسبة الخدمات الممتازة (4\%) فئ

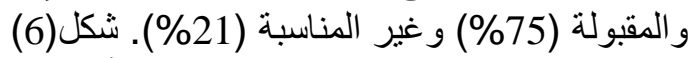

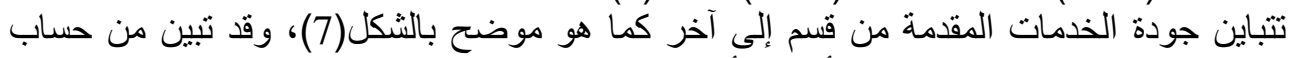

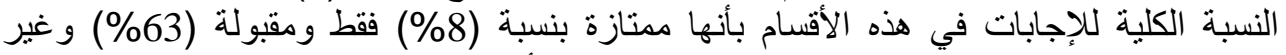
المناسبة (29\%) ويرجع ذلك إلى نقص المكونات والأجهزة الطبية وهي نسبة مقاربة الإنة لإجابة السؤال السابق مما بؤكد صحتها.

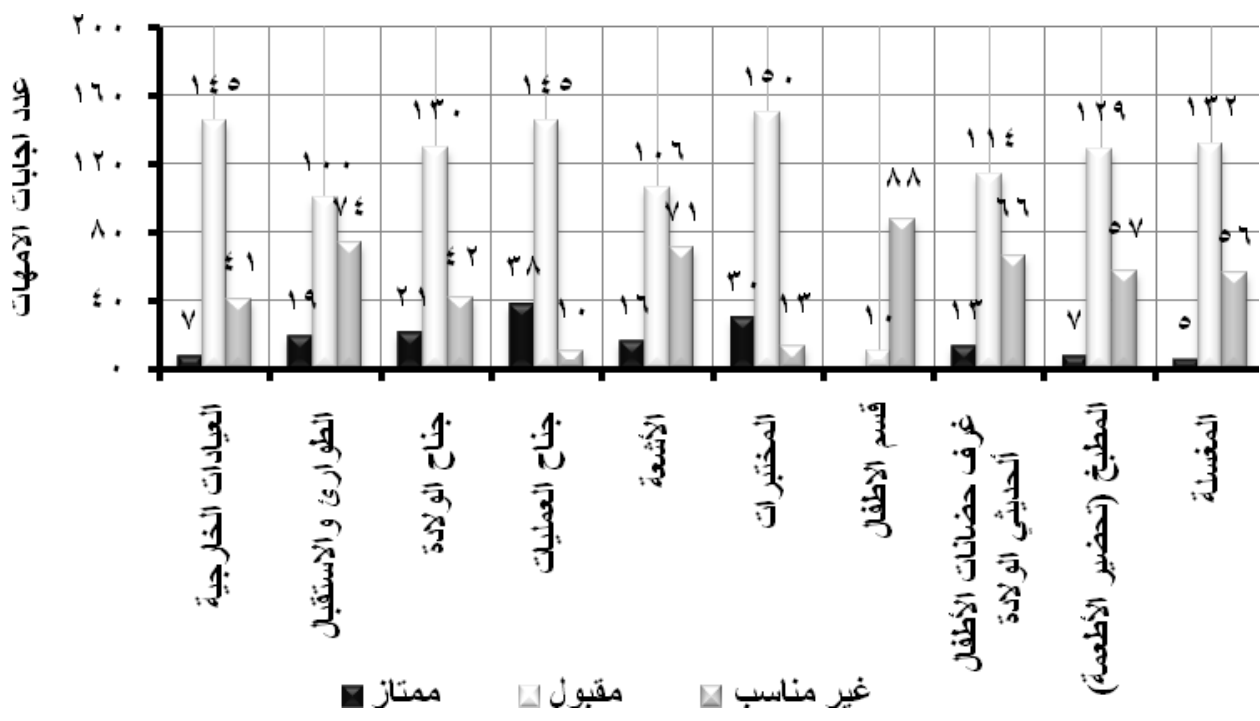

شكل(7): نتائج الاستبيان حول جودة الخدمات بأقسام المستشفى.

إن مشكلة توفير الخصوصية بالمستشفى من الأمور الحساسة بالنسبة للأم ومن خلال إجابة

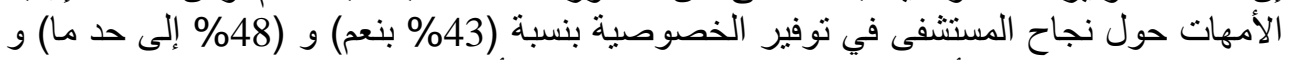
(9\% بلا)، ويشير إلى أن المستشفى توفر الخصوصية للأمهات، ولكن بسبب قلة الإنة الإمكانيات لم

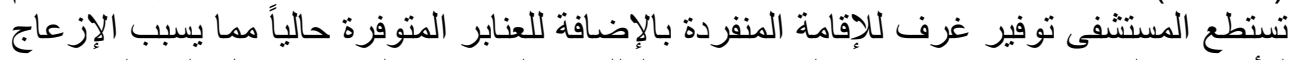

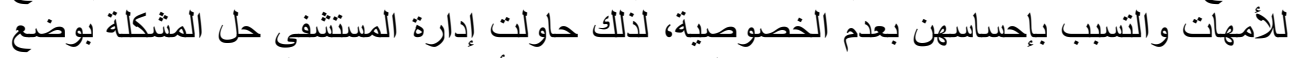

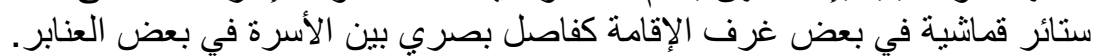

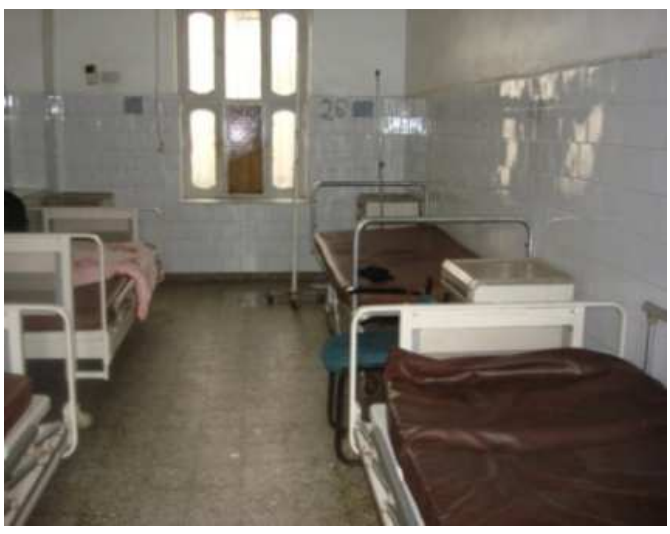

شكل (9): العنابر التي لم يتم توفير ستائر قماشية فيها لتعزيز الخصوصية لتمبية

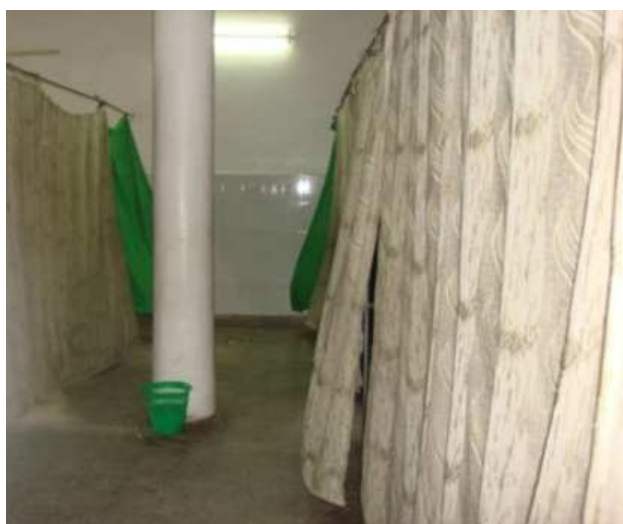

شكل (8): العنابر التي نم توفير ستائر قماشية فيها كحل مؤقت لتعزيز الخصوصية توفيز 


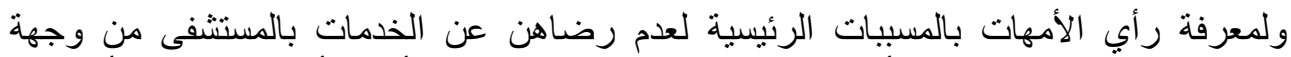

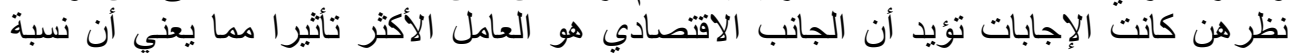

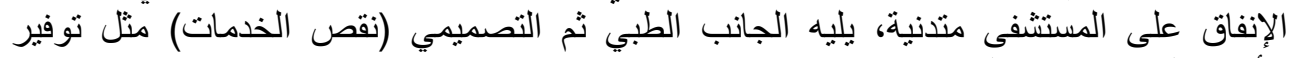
الأقسام المتخصصة و المساحات و غيرنة هانها.

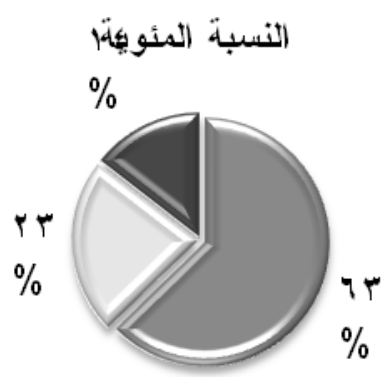

شكل (10): العو امل المؤثرة على مستوى الخدمات بالمستشفى من وجهة نظر الأمهات.

$$
\begin{aligned}
& \text { عامل اقتصادي } \\
& \text { الكادر الطبي } \\
& \text { نقص الخدمات }
\end{aligned}
$$

2-3- من وجهة نظر الأطباء والممرضين:

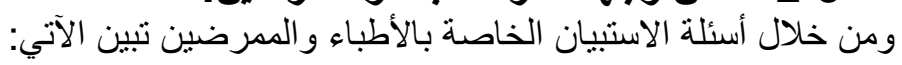

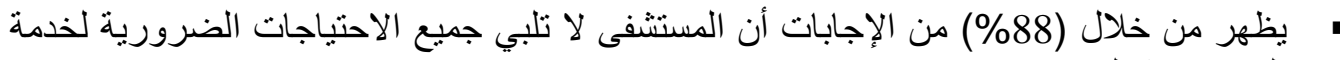

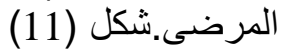
أكدت (86\%) من الإجابات أن بعض الأقسام بالمستشفى لا تستطيع الإيفاء بجميع الاحتياجات مما

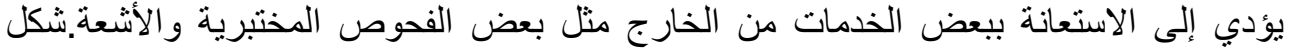

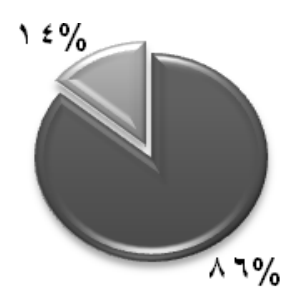

نعم

$\square$

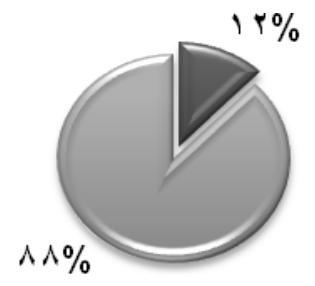

曰 $\square$ ن

شكل رقم (12):النسبة المئوية للاجابة عن الاستعانة

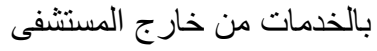
شكل رقم (11):النسبة المئوية للاجابة عن تلبية المستشفى لجميع الاحتياجات الضرورية لابنة

تحتاج أقسام المستشفى للتوسع بسبب نقص مساحتها الحالية سوى كان على مستوى الأقسام أو على مستوى المبنى وكانت نتيجة الإجابات كالتالي: لتاني 


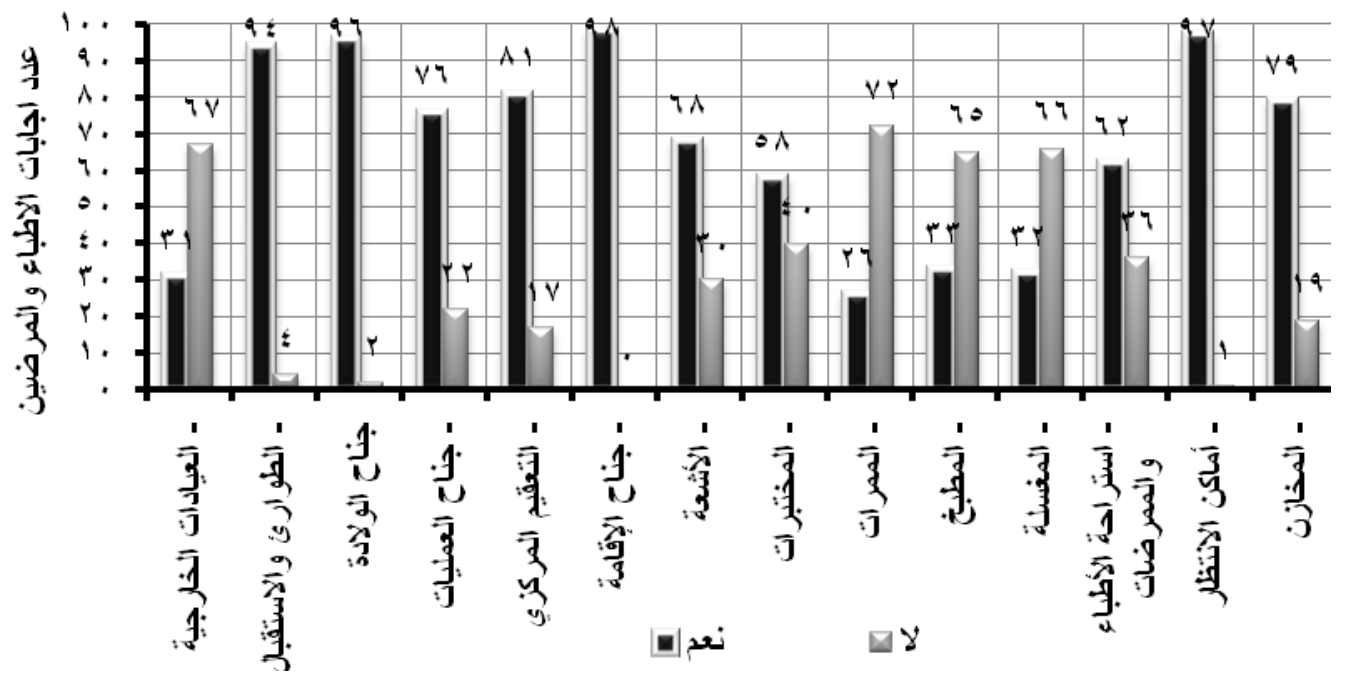

شكل رقم (13): الأقسام التي تحتاج إلى توسع بالمساحة حسب نتائج الاستبيان.

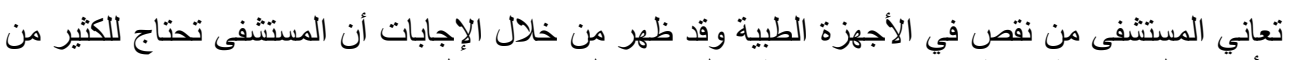
الأجهزة الضرورية بنسبة (98\%)، مما يؤثر على تقديم الخدمات بشكل جيد.

3-3-3 من وجهة نظر الباحثة:

من خلال المسح الميداني والملاحظة الثخصية لموقع المستشفى ومكوناتها يمكن تحديد وتصنيف

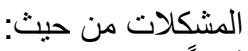

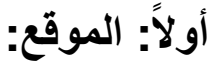
بني المستشفى قديما بضو احي المدينة، ومع مرور الوقت وازئ المياد الكثافة السكانية والتوسع العمر اني خلال فترة

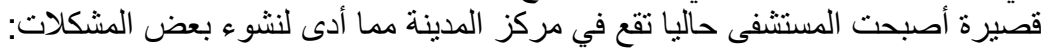

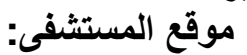
تقع المستشفى بمركز المدينة وهي منطقة مزدحمة بالسكان ويلاحظ ارتفاع نسبة الضوضاء بالمستشفى وذللك للأسباب الثنالية:

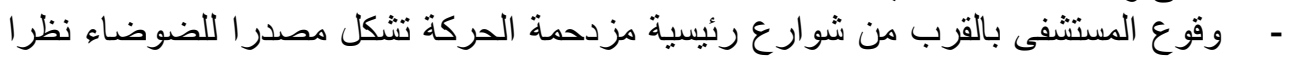

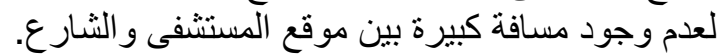

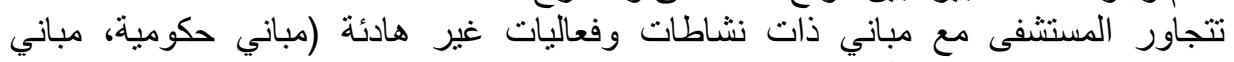

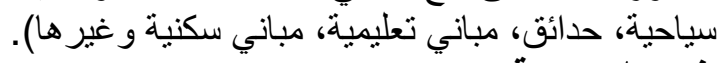

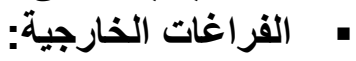

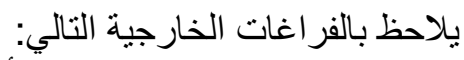

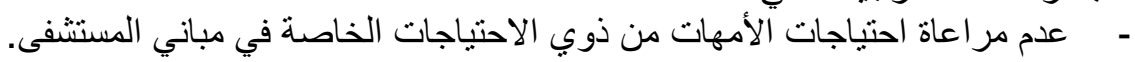

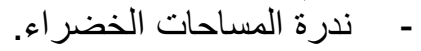

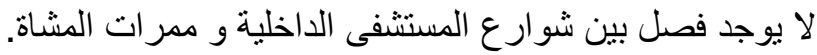

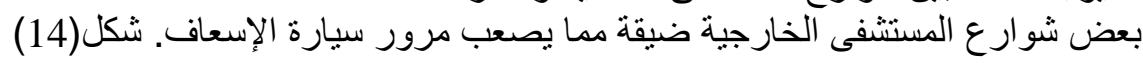

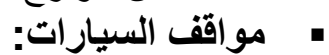
لا يوجد تنظيم لمو اقف السيارات ويلاحظ من الثكل(15) وقوف السيارات عشو ائيا بداخل المستشفى. 


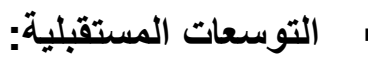

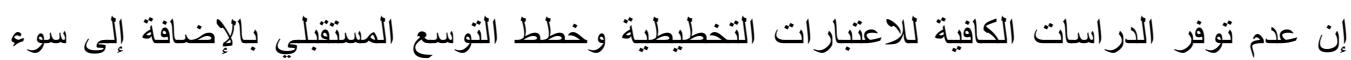

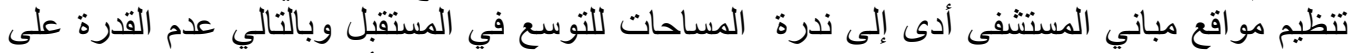

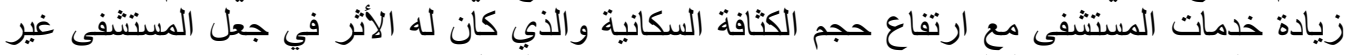

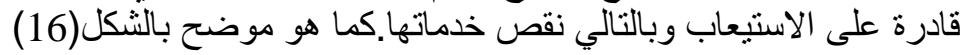

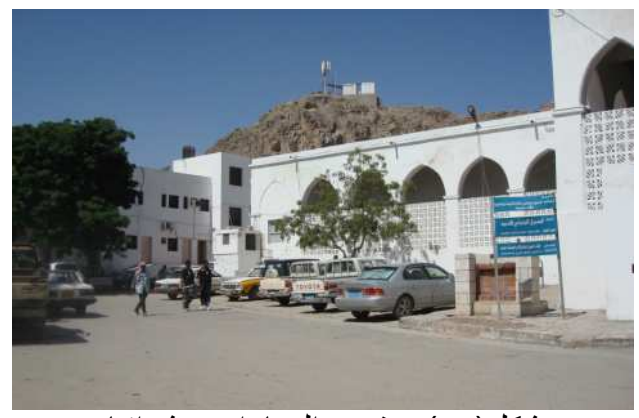

شكل(15): وقوف السيار ات عشو ائيا.

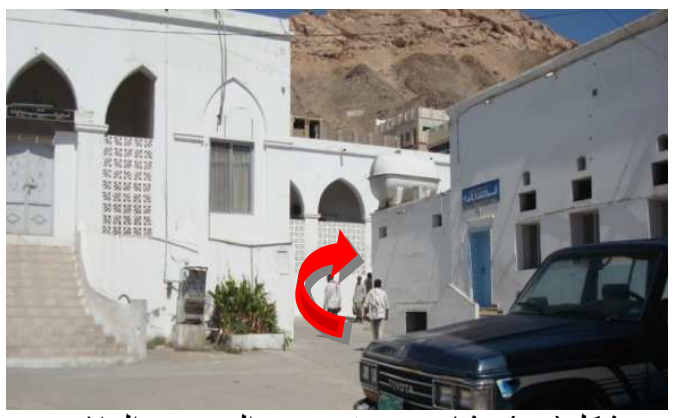

شكل(14): شارع ضيق يؤدي إلى مبنى الو لادة.

ثانياً: العوامل التصميمية:

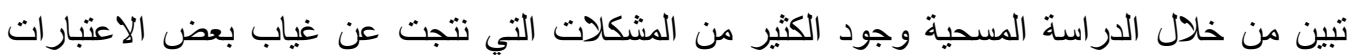

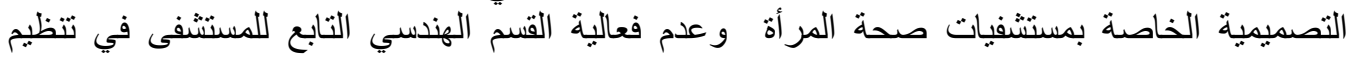

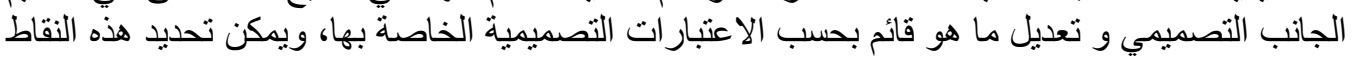

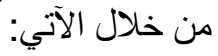
أ- وحدة التشخيص والعلاج:

من خلال الثكل (16) و و(17) يمكن ملاحظة النقاط التالية:

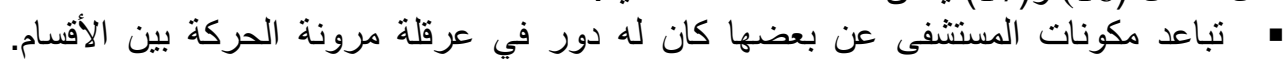
وبسبب ذللك نتجت مجمو عة من المشكلات:

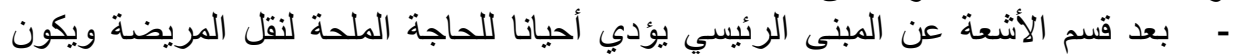

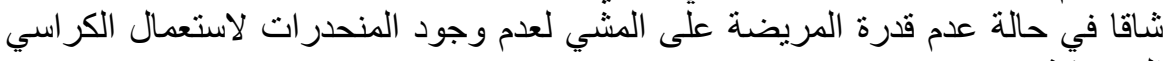

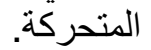
- عدم الربط بين قسم العيادات الخارجية والأشعة و المختبرات.

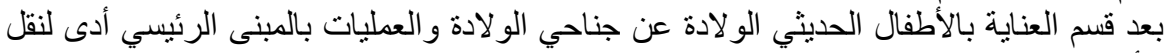

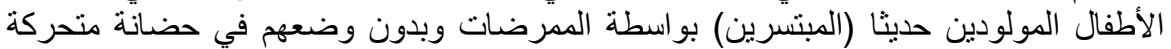

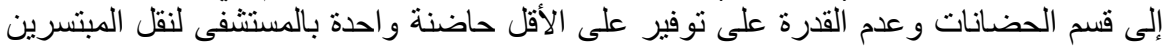
إلى القسم الخاص بهم بسبب عجز المستشفى عن توفير ها. 

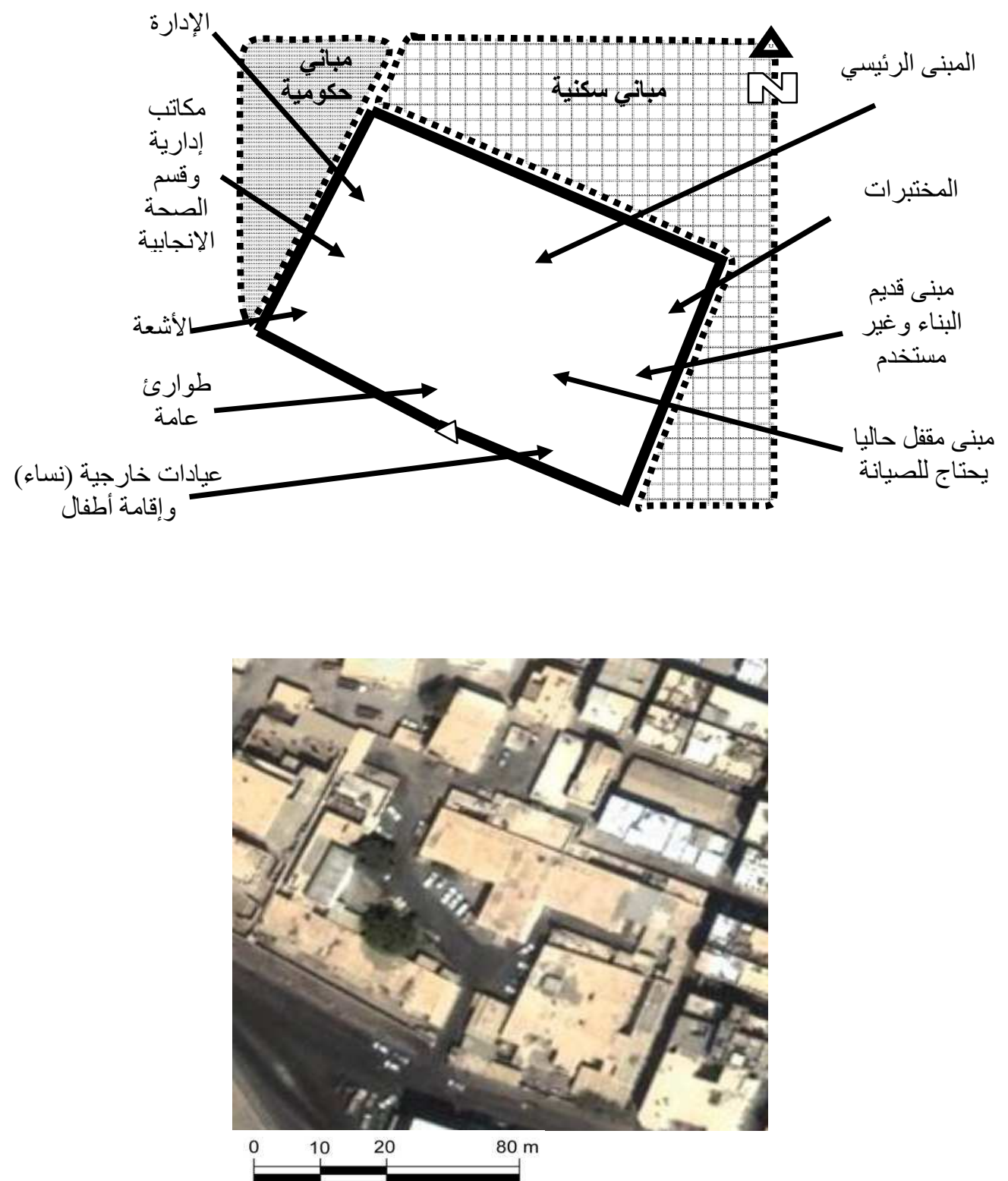

شكل(16): موقع المختبر ات والأشعة بالنسبة للمبنى الرئيسي بمستشفى المكلا للأمومة . 


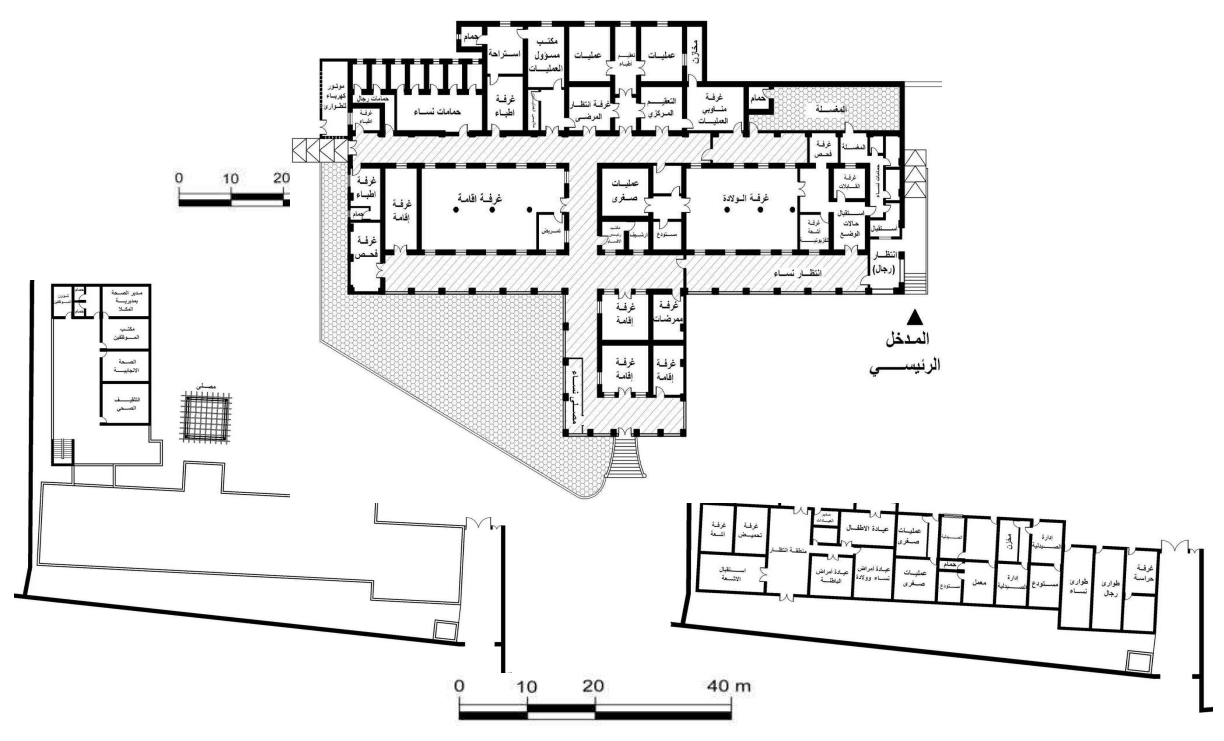

الدور الأرضي و الأول لمبنى الطو ارئ العامة ومبنى الصحة الإنجابية[2]
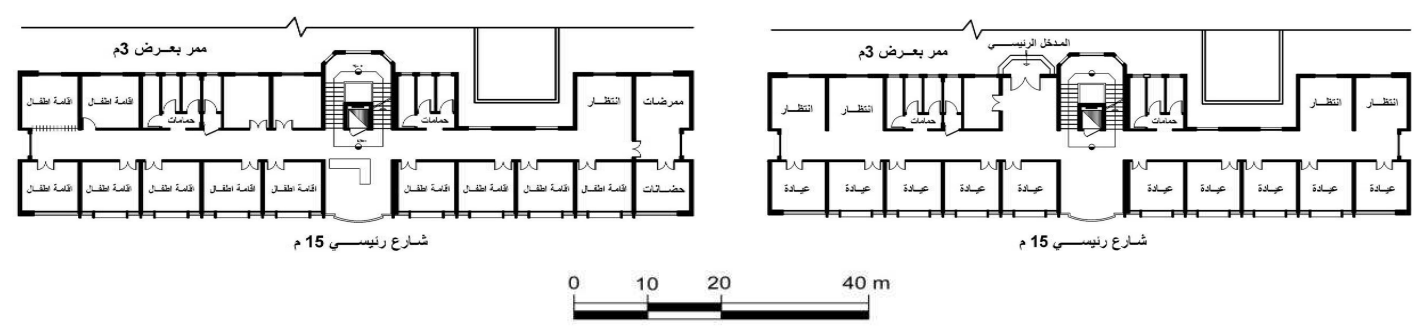

المساقط الأفقية للدور الأرضي و الأول لمبنى العيادات الخارجية وإقامة الأطفال
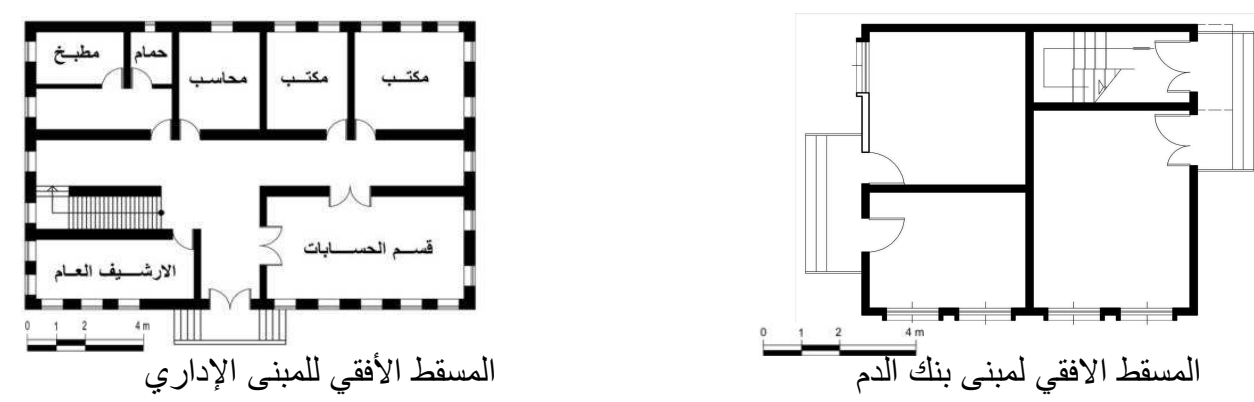

شكل(17): المساقط الأفقية لمباني مستشفى المكلا لصحة المرأة 


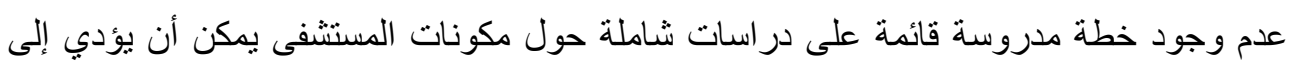

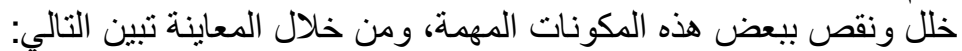

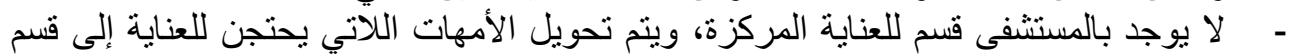

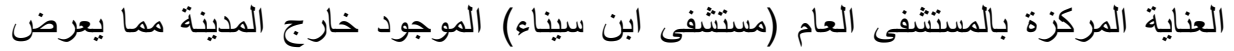

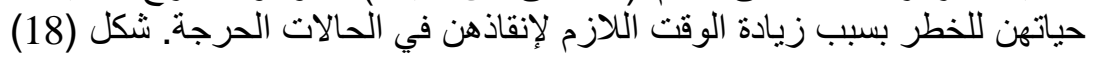

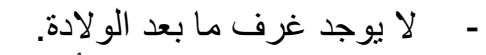
- - ل - ل الا يوجد قسم الإسعافات الأولية.

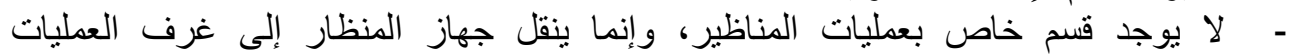

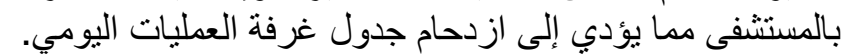

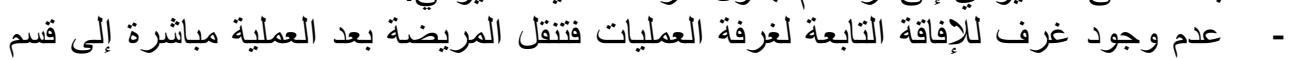

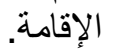

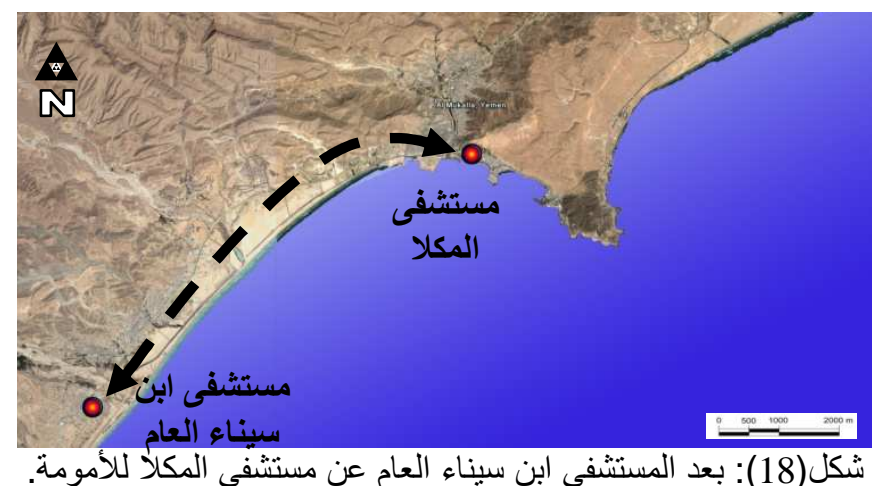

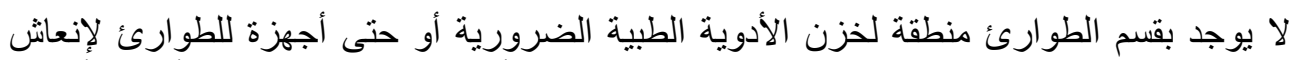

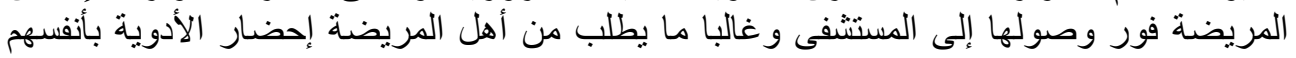
من الصيدلية. مبنى العيادات الخارجية تبلغ مساحته (414.9 م²) و هو من المباني التي بنيت حديثا إلا أن هناك نقص بالأجهزة الطبية الموجودة فيها.

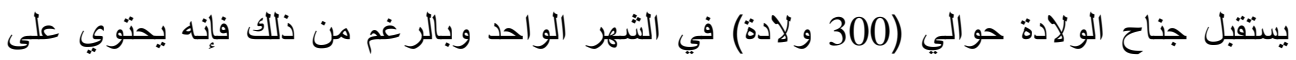

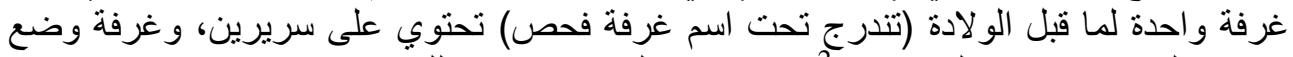

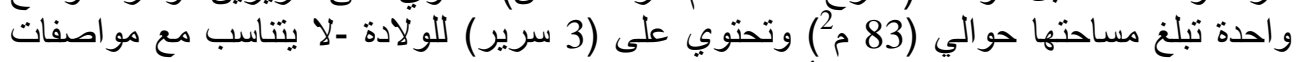
سرير الولادة- بالإضافة إلى نقص الأجهزة الطبية. نقص الأجهزة الطبية بالمستشفى و الأجهزة الإحتية الإنياطية مثل: - - أجهزة الأشعة المقطعية.

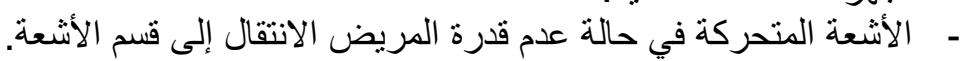

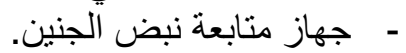
- ـ أجهزة العناية المركزة.(المونينور -جهاز التنفس الاصطناعي-أجهزة شفط السوائل).

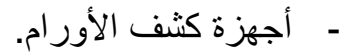

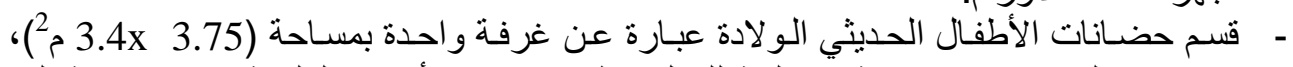

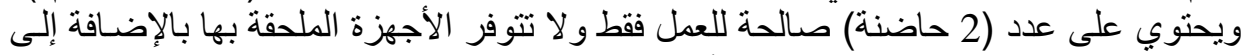
غرفة للممرضات تحنوي على خز ائن للادوية.

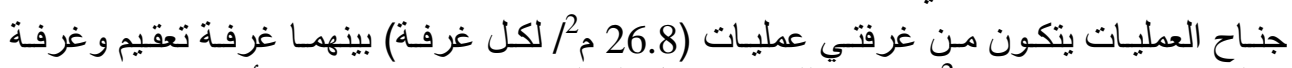

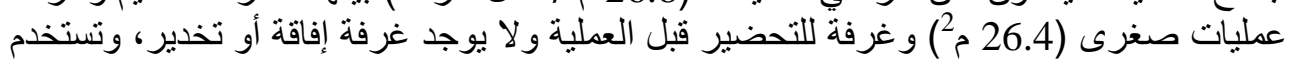




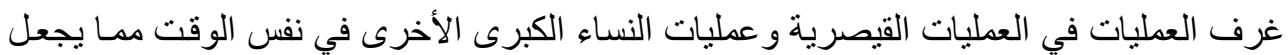

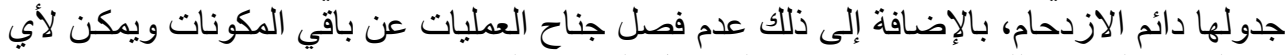

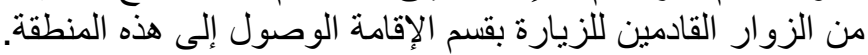
نقص بمساحة الأقسام الحالية.

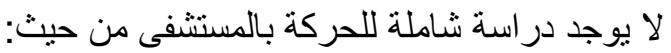
-

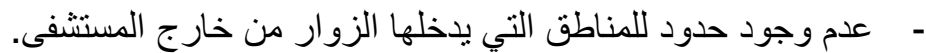

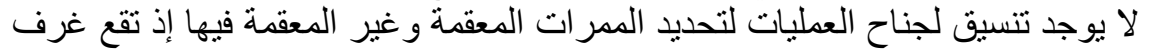

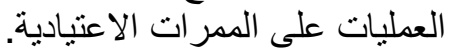

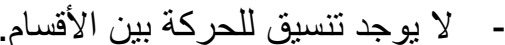

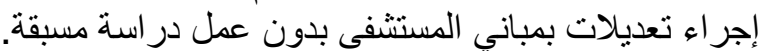
عدم وجود مختصين للإنشر اف على عمليـات الإضـافة و التعديل الهندسي للمباني و الموقع وكل مـا يتعلق بمبنى المستشفى.

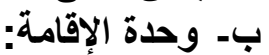

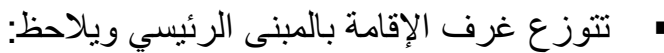

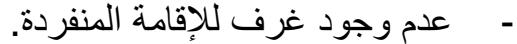

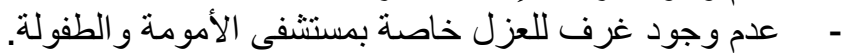

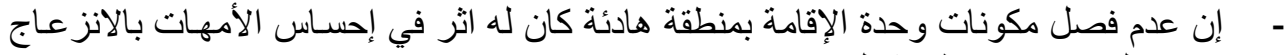
بسبب الضوضاء (انظر شكل(19)).

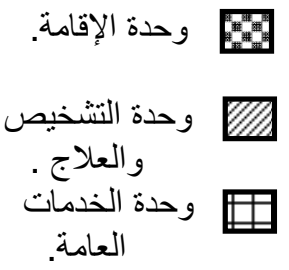

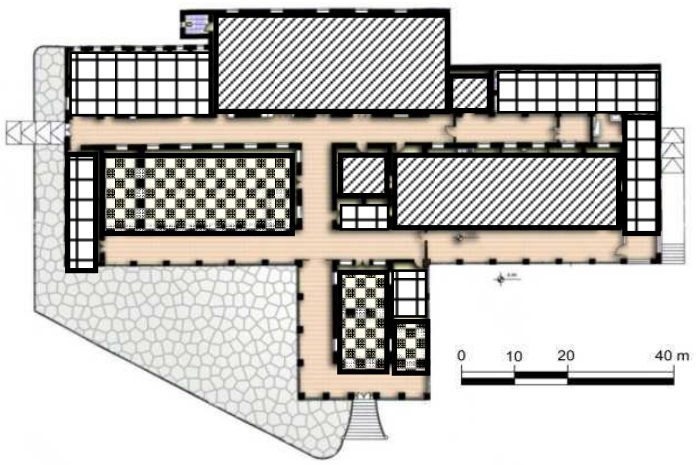

شكل رقم(19): مبنى الأمومة و الطفولة

ج- وحدة الخدمات العامة:

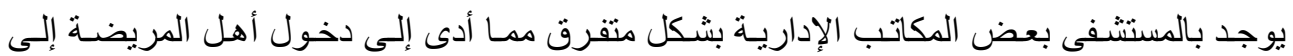

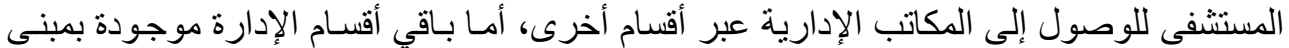
منفصل قريب من المبنى الرئيسي.

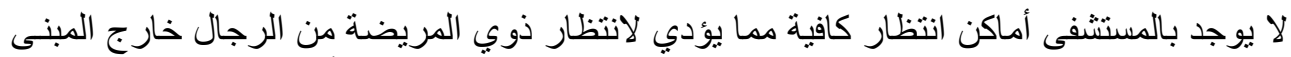

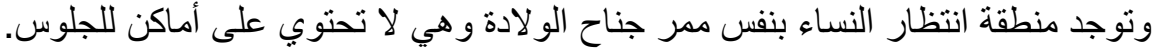
لا يوجد بالمستشفى تكييف مركزي بسبب تباعد مكونات المستشفى عن بعضهـا و الاكتفاء بوحدات التكييف المنفردة وهي قديمة جدا وتحتاج إلى صيانة وتجديد.

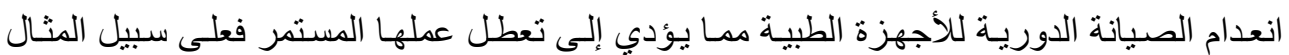

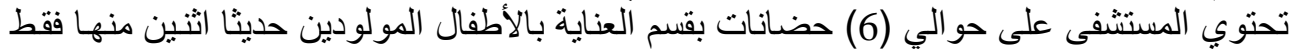

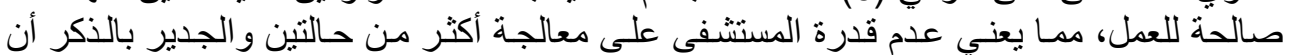


الأطفال ييقون بالحاضنة إلى حين تعافيهم مما يعني انه يتم تحويل الأطفال الآخرين إلى مستشفيات خاصة. التعقيم المركزي عبارة عن غرفة واحدة بمساحة (4.5 4.8 2.2 و هي صغيرة ولا تتضمن جميع أجهزة للتعقيم. يعتبر المطبخ عمليا شبه منوقف. للفعة.

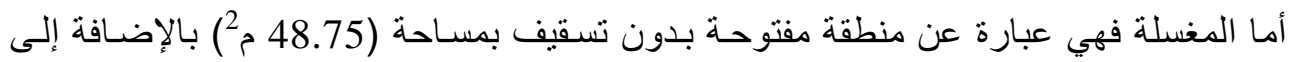

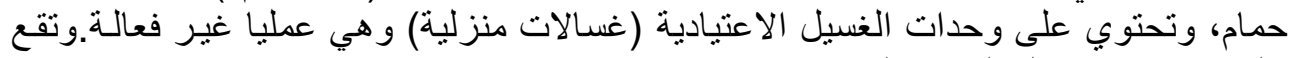
بالقرب من جناح العمليات و والو لادة.

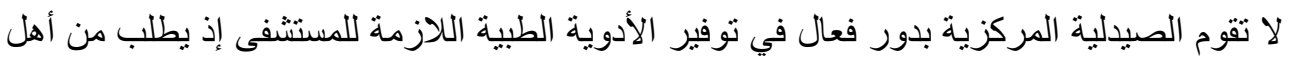

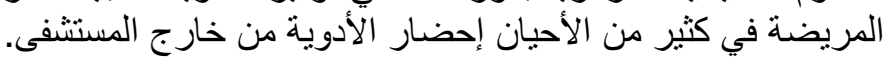

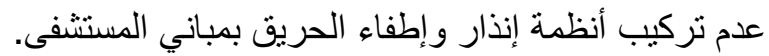
لا يوجد بجناح العمليات والو لادة نظام شفط وتغبير الهو اء الملوث.

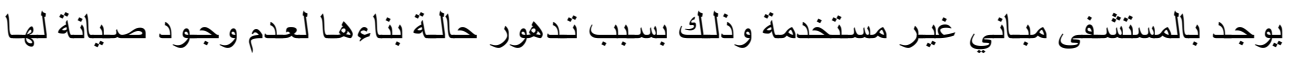

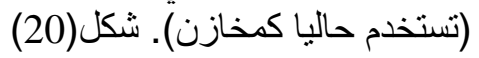
انعـدام الصـيانة و النظافـة الدوريـة لـبعض المبـاني مدـا أدي إلـى تـدهور وتـردي بناءهـا، انظـر شكل(21).

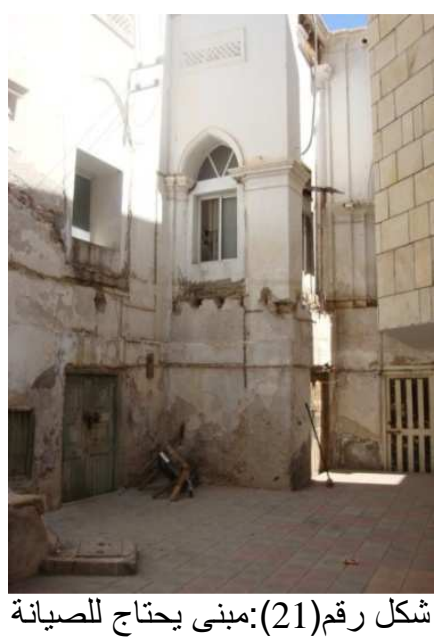

شكل رقم(21):مبنى يحتاج للصيانة

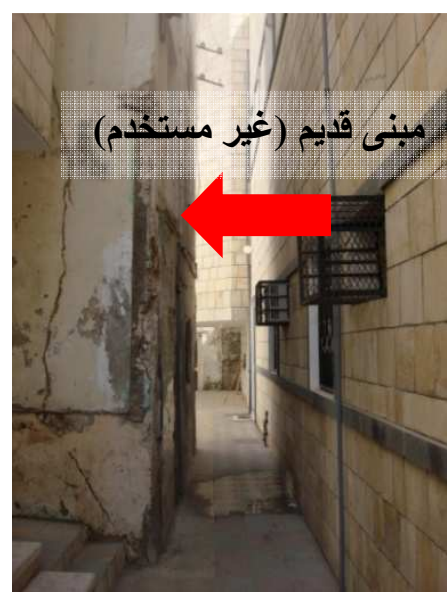

شكل رقم(20):مبنى غير مستخدم

بسبب قدم بناؤه

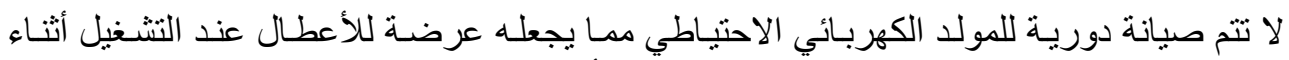

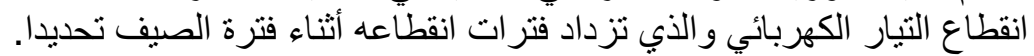
لا تحتوي المستشفى على خزانات أرضية ذات سعة كافية لخزن المياه في حالة انقطاع شبكة المياه

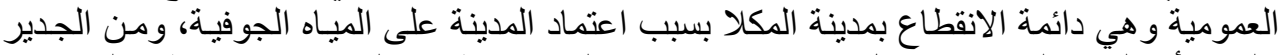

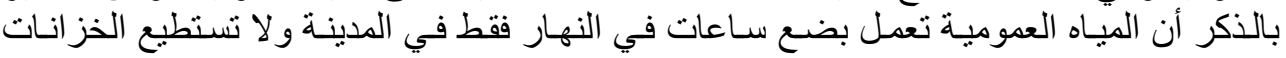
الاعتيادية التي تمنلكها المستشفى من تغطية احتياجاتها. شبكة مياه المجاري و الصرف الصحي متهالكة وتحتاج إلى تغيير. 
ثالثناً: العوامل المناخية:

إتأتزر المرضى بالعو امل المناخية، من خلال الآتي:

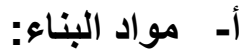

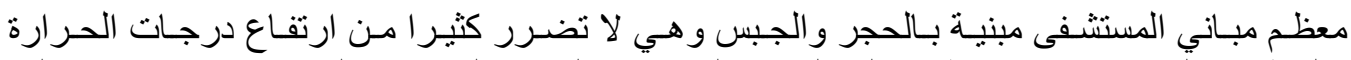

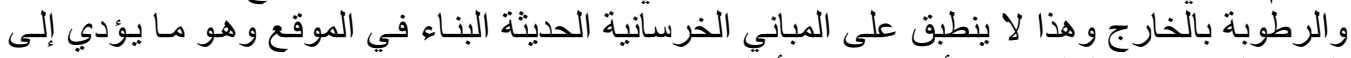

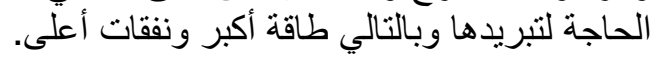

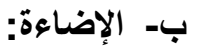

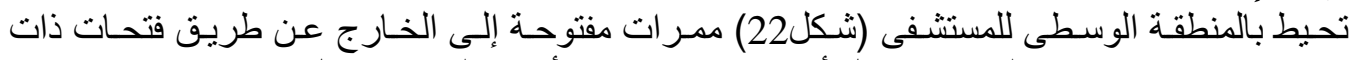

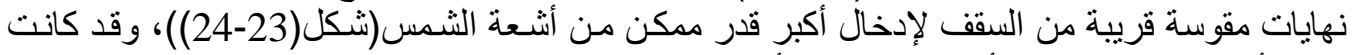

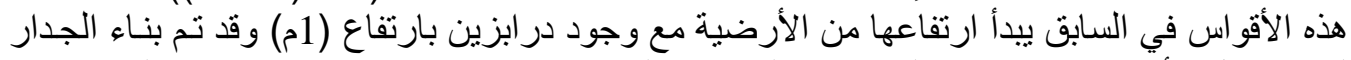

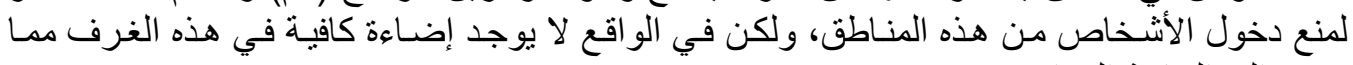

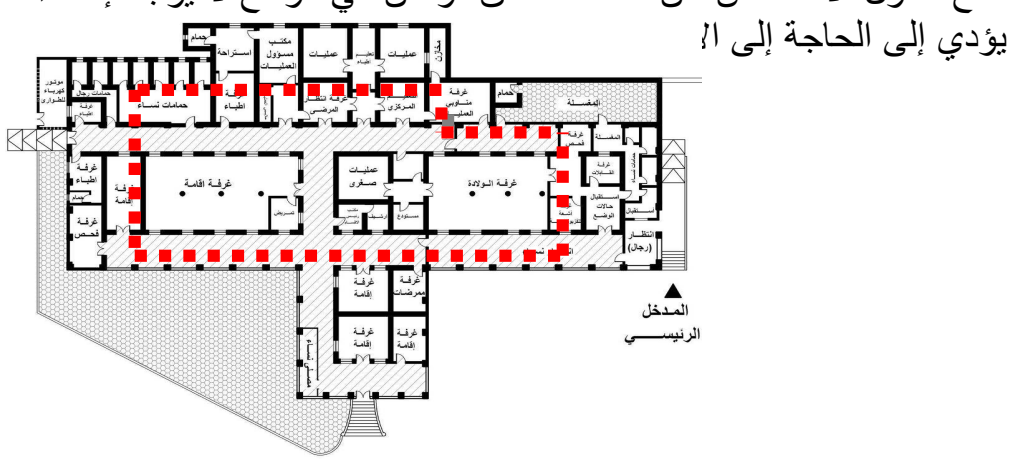

شكل(22):المنطقة الوسطية بالمستشفى تحتاج لمعالجة الإضاءة

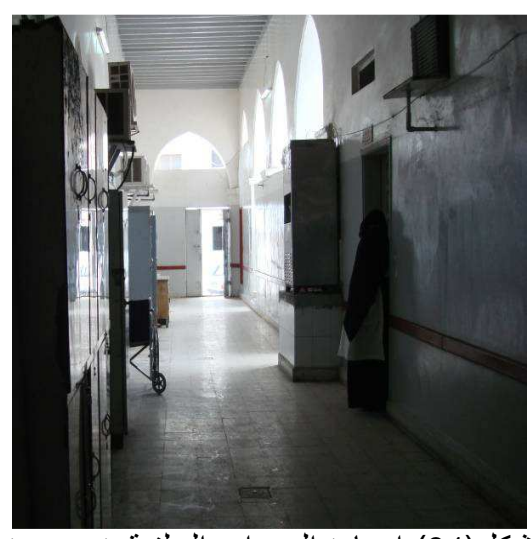

شكل(24):إضاءة الممرات الخلفية غير جيدة

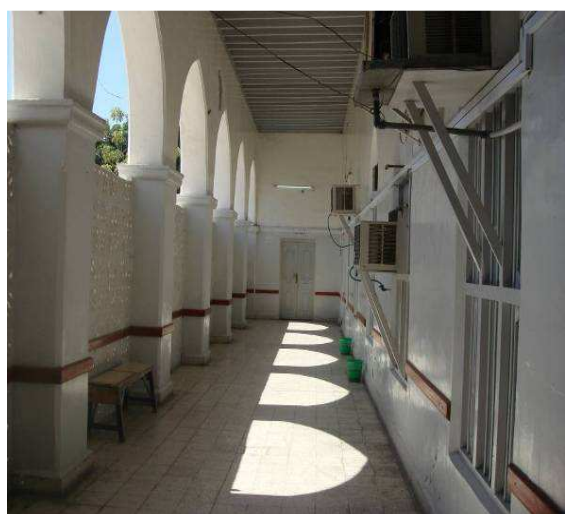

شكل(23):الإضاءة تصل للممر الأمامي ولا تصل إلى

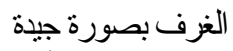

رابعا: العوامل الاجتماعية:

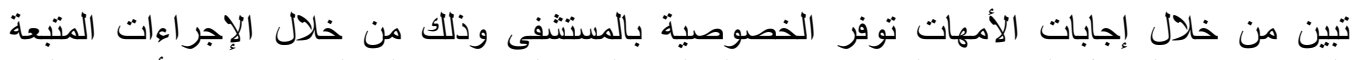

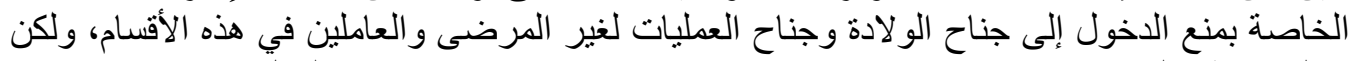

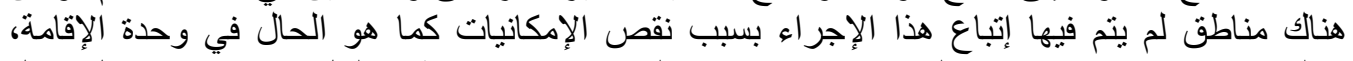

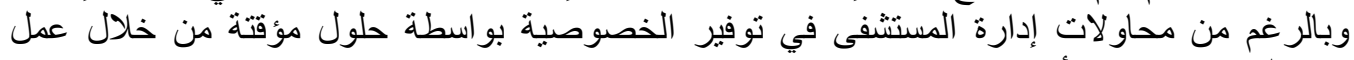
فو اصل قماثية بين الأسرة 


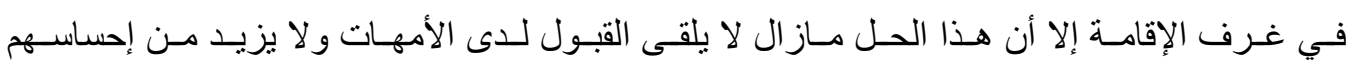
بالخصوصية.

\section{خامسا: العوامل الاقتصادية:}

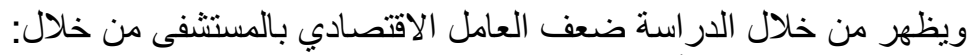

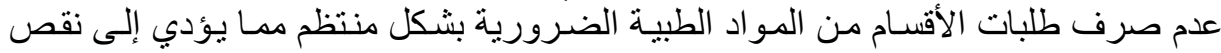

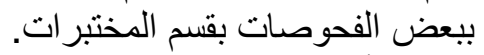

نقص الأجهزة الطبية بالمستشفى مما يؤثر في القدرة على تحسين خدمات المستشفى.

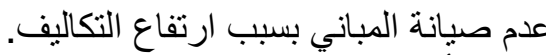

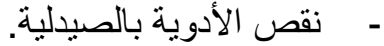

\section{4- اتجاهات الحلول:}

تم مـن خـلال النقاط السـابقة التعرف على أهم المشكلات وفي هذه النقطـة سيتم تقديم بعض الحلول

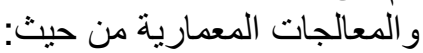
1-4- اتجاهات الحلول الخاصة بن بالموقع: يمكن تقسيم الحلول الخاصة الجلول بالموقع إلى عدة نقاطع:

أـ- معالجة الضوضاء الخارجية:

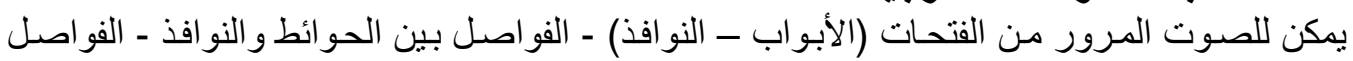

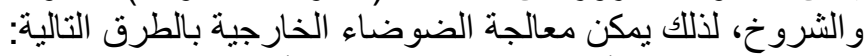

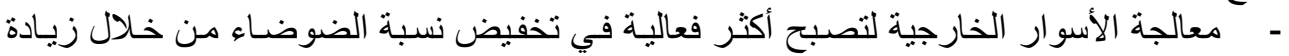

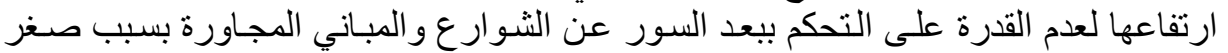

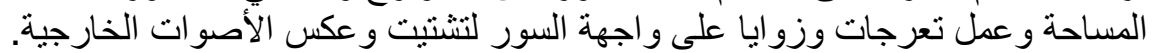

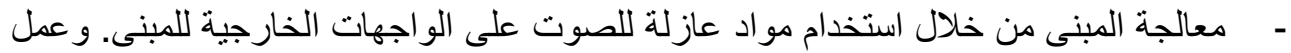

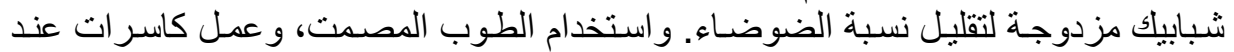

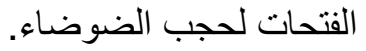
ب- معالجة الضوضاء الاخلية:

لمعالجة الضوضاء الداخلية يمكن عمل أحد الحلوف الحولة التالية:

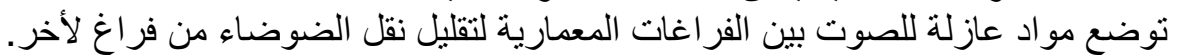

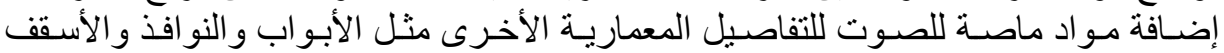

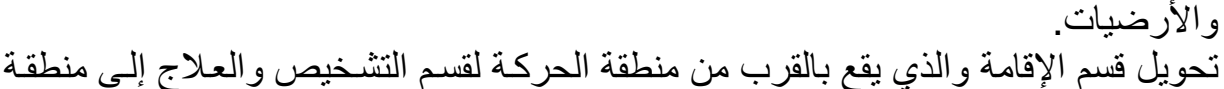

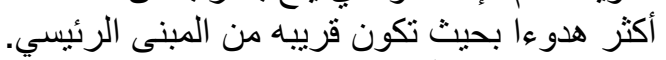
ج- الفزاغات الخارجية:

تعتبر الفر اغات الخارجية من المناطق التي يمكن تنظيمها للاستفادة منها وتنسيقها من خلال: زيادة المساحات الخضر اء إثات بالموقع.

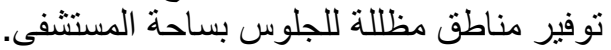
فصل شو ارع المستشفى عن ممر ات ات المشاة.

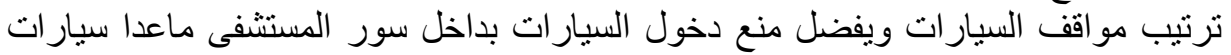

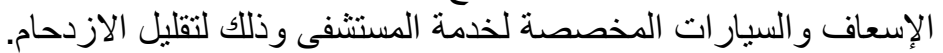
- توسيع ممر ات المسنشفى الضيقة والتي يصعب مرور سيارة الإسعاف من خلالها. 
مر اعاة ذوي الاحتياجات الخاصة من خلال[1]:

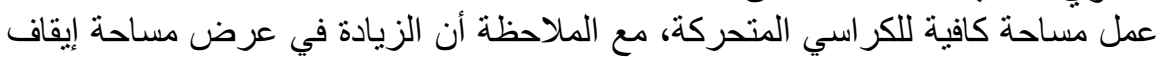

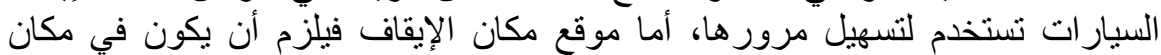

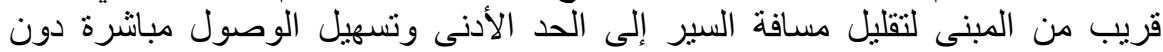
الحاجة للمرور بين السيار ات الأخرى.

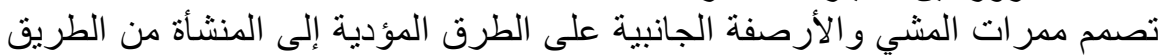

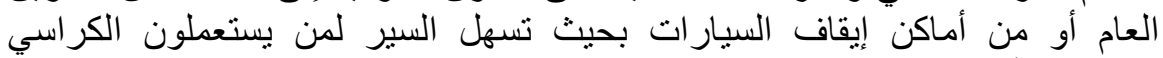

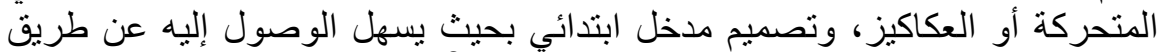

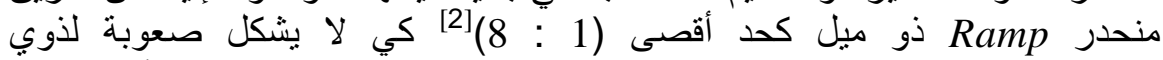

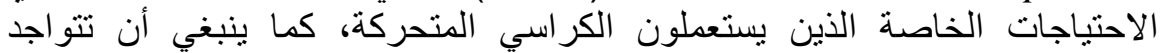
الدرجات Steps بجانب وجود الأبن المنحدر.

$$
\text { د- الت التوسعات المستقبلية: }
$$

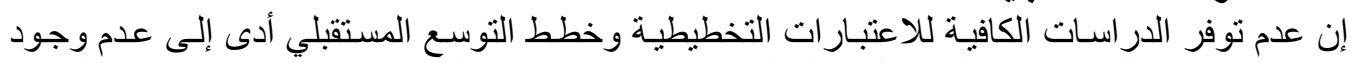

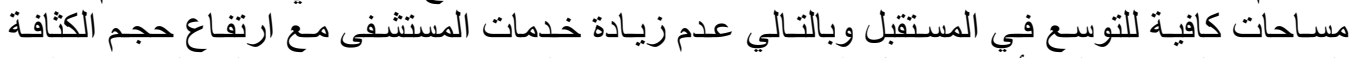

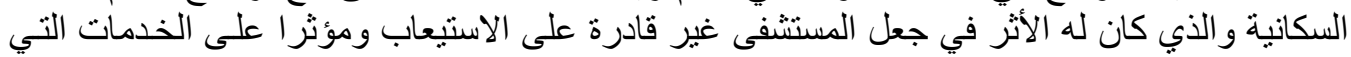

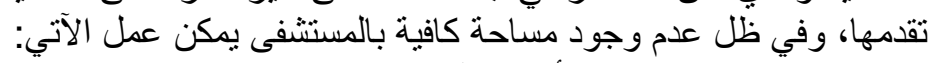

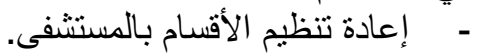

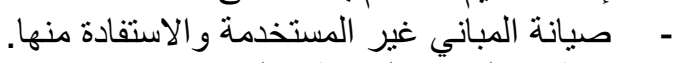
- - توظيف المباني المحيطة بالمستشفى.

2-4-4 اتجاهات الحلول الخاصة بالعوامل التصميمية:

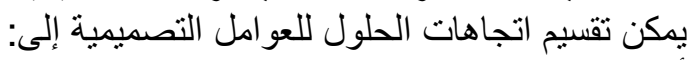
أ- وحدة التشخيص والعلاج: عمل دراسات شاملة لتوفير المكونات و الأقسام غير الموجودة بالموقع مثل:

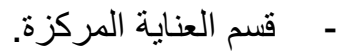
- - - مسم الإسعافات الأولية.

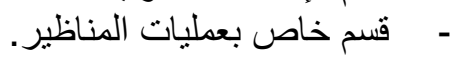
- - مرف ل لإفاقة تابعة لغرفة العمليات. توفير الأجهزة الطبية الناقصة والضعة والضرورية في كل قسم مثل: - - - الأشعة المتحركة في حالة عدم قدرة المريض الانتقال إلى قسم الأشعة.

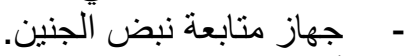
- - أجهزة العناية المركزة.(المونيتور -جهاز التنفس الاصطناعي-أجهزة شفط السوائل). - - مهزة كثف الأورام. - حضانات الأطفال الحديثي الولادة. توسعة مساحة أقسام الولادة التي تحتاج لمساحات الضادة إضافية، وتحتاج عملية التوسع لدراسة شاملة لموقع المستشفى ويمكن اقتر اح الحلول التول التالية: 
- إعادة استخدام بعض المباني التي تحتوي على وظائف طبية لا تتتمي لمستثفى الأمومة

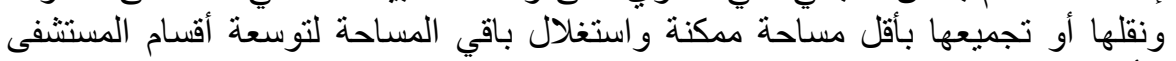

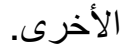
تجميع المكاتب الإدارية بمبنى واحد لاستغلال مساحتها.

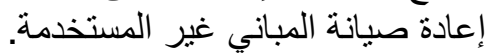

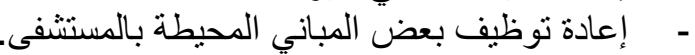

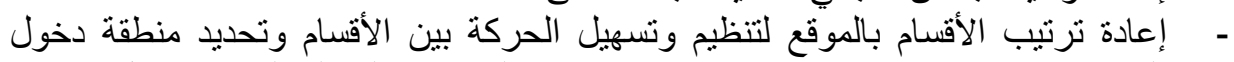

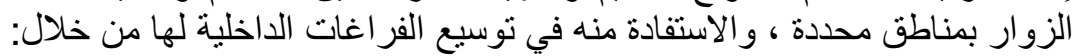

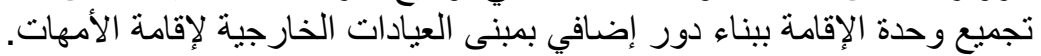

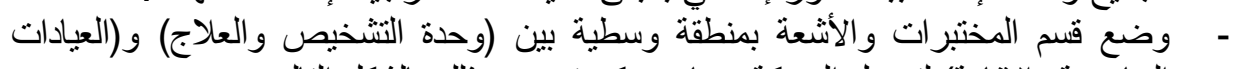

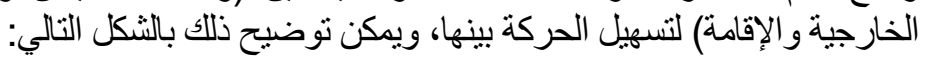
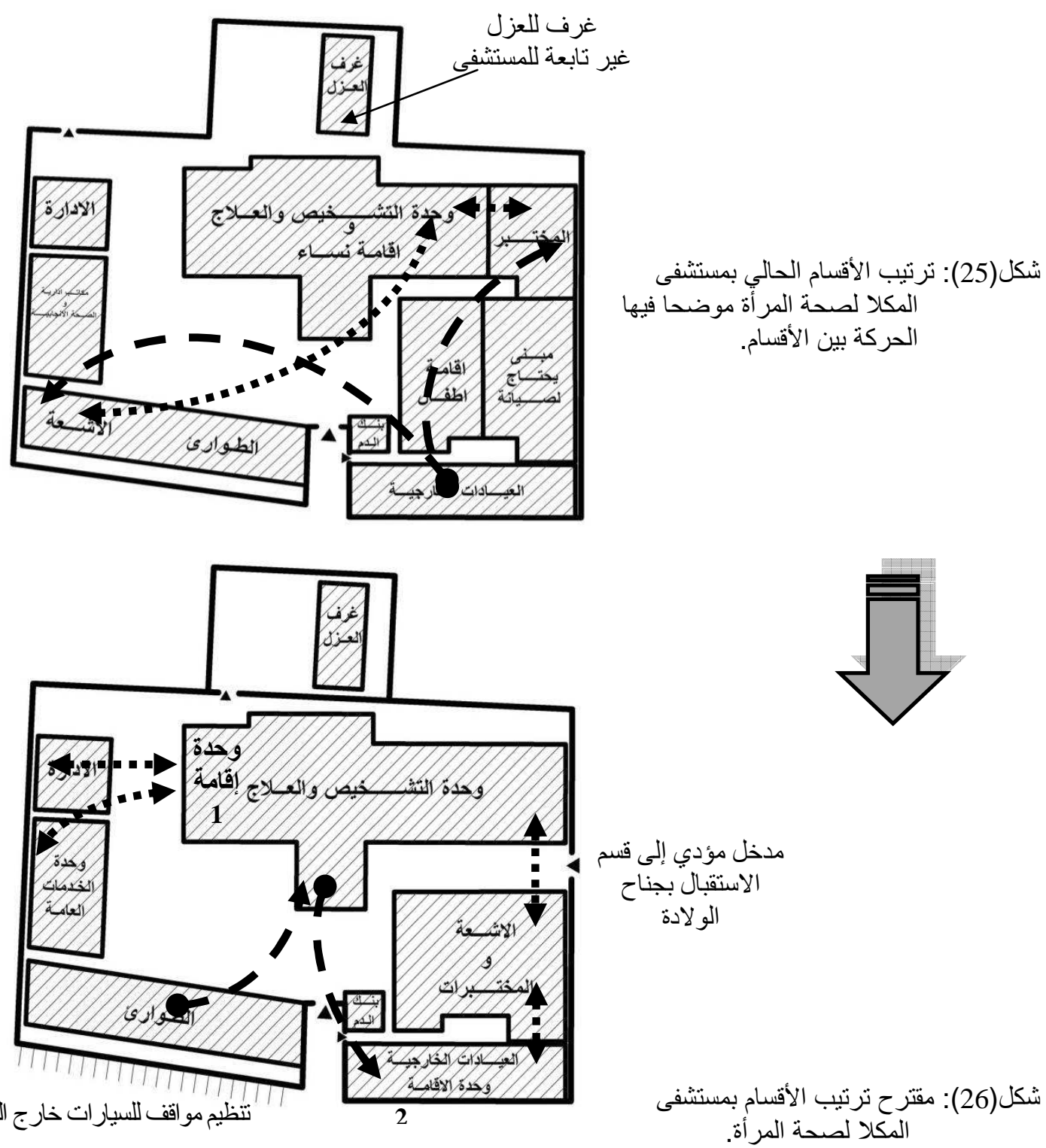


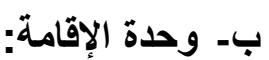

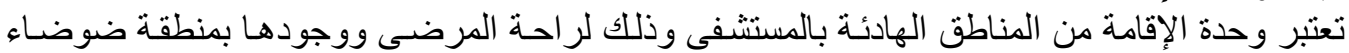

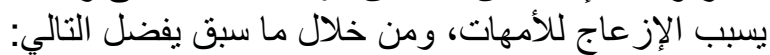

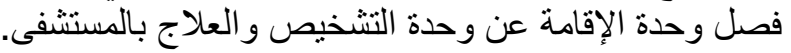

تقسيم غرف الإقامة بمنطقتين:

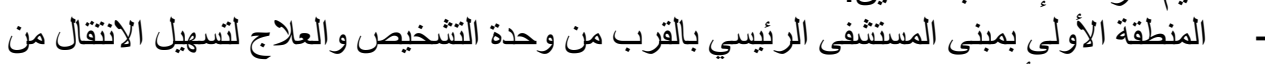

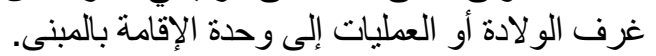

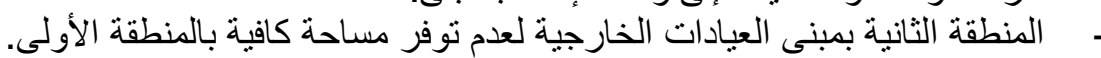
توفير غرف للإقامة المنفردة. ج- وحدة الخدمات العامة:

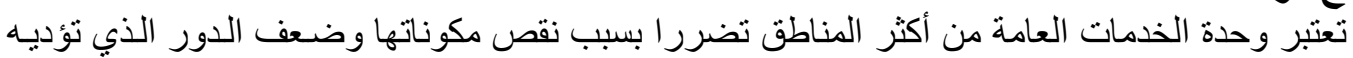
ل الذلك لابد من عمل عدة معالجات:

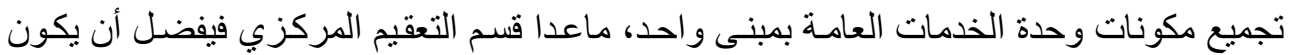

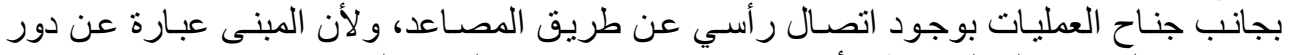

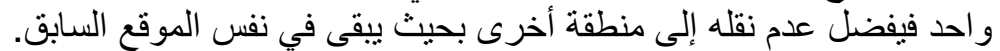
تفعيل دور القسم الهندسي لصيانة المباني و الحفاظ عليها من خلال إعطاء الإمكانيات و الصـلاحيات

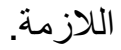

توفير ورش صيانة للنقاط التالية:

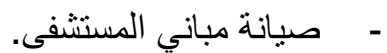

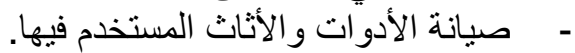

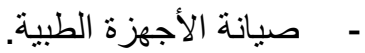

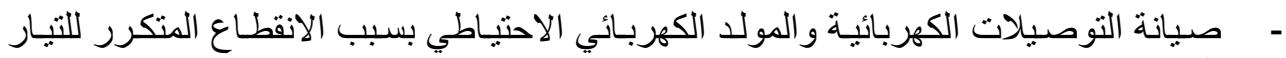
الكهربائي. توفير خزان للمياه ذو سعة عالية لاستخدامه في وقت انقطاع شبكة المياه العمومية.

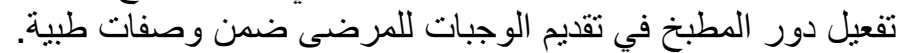

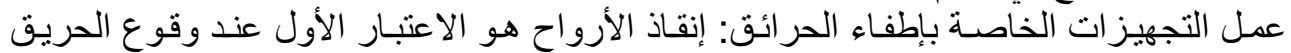

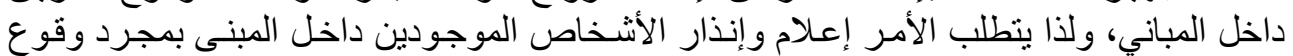
الحريق بواسطة أجهزة إنذار الحريق حتى يستطيعون مغادرته قبل أن تمند النبران وانتين التنتشر ويتعذر

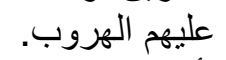

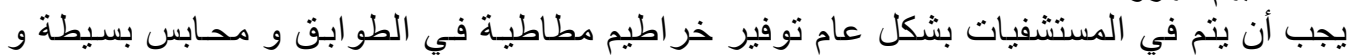

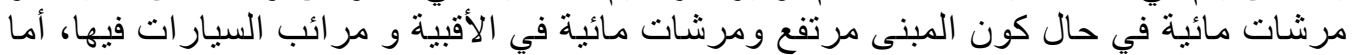

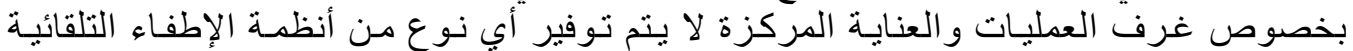

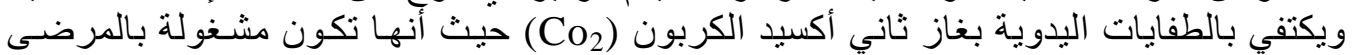

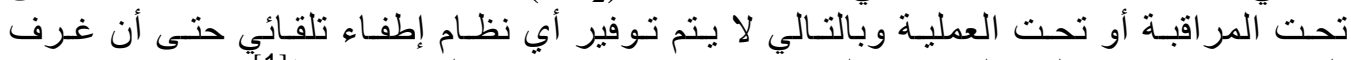

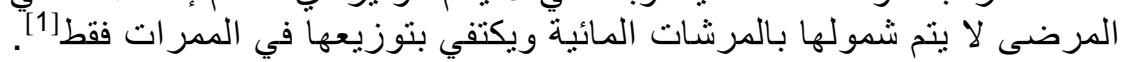

3-4-4 اتجاهات الحلول الخاصة بالعوامل المل المناخية:

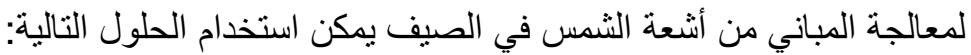

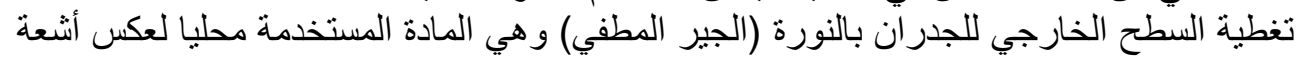
الثمس و الحماية من درجات الحر ارة المرتفعة بالخارج. 


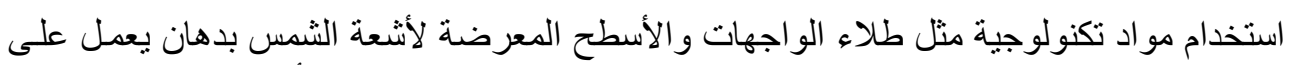

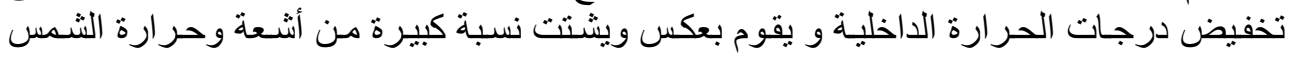

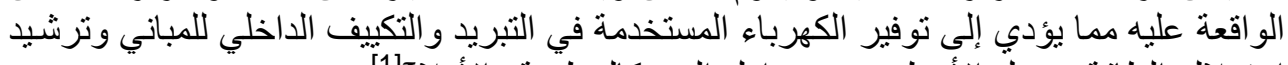

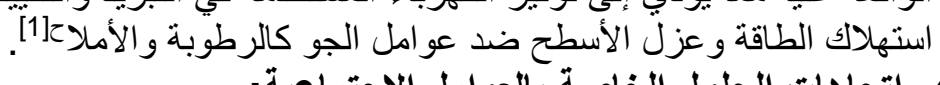

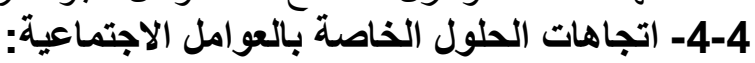
لزيادة إحساس الأمهات بالخصوصية بفضل الآتي:

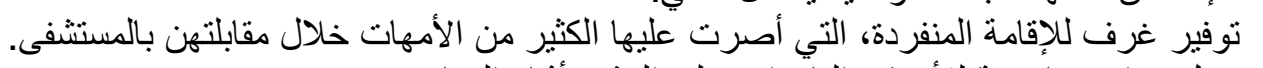

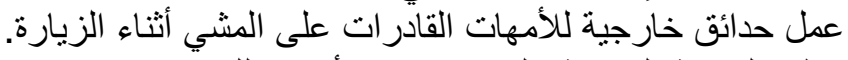

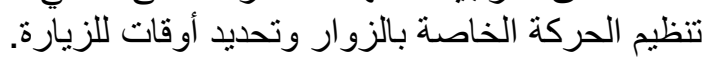

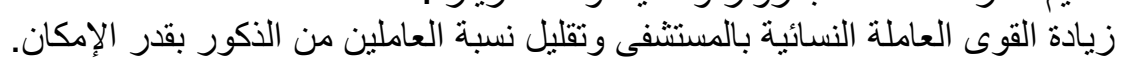

\section{5- التتائج والتوصيات:}

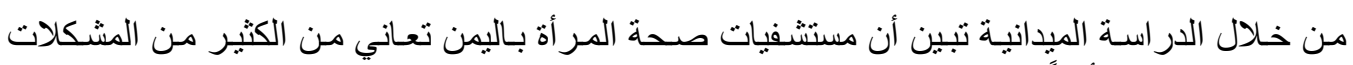

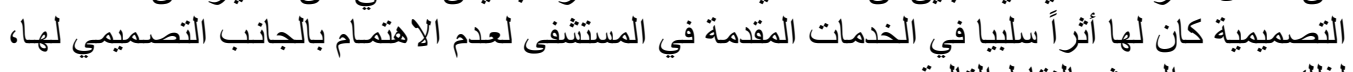
لذلك يوصي البحث بالنقاط التالية: لهئ:

تفعيل دور مكتب وز ارة الصحة بالمحافظة لإجر اء الداء الدر اسات و البحوث وتطوير المباني الصحية.

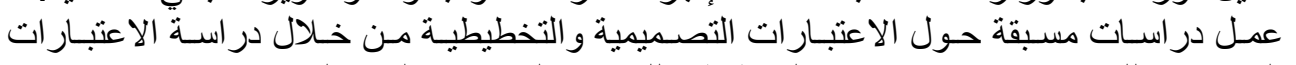

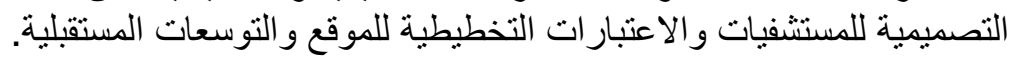

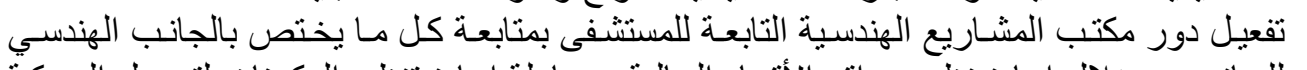

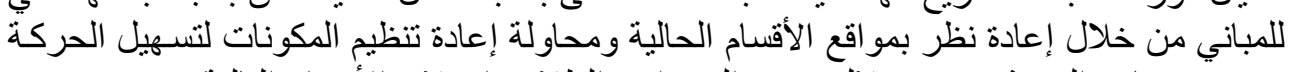

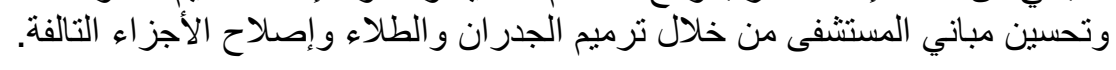

$\left[{ }^{1}\right]$ http://www.arab-eng.org/vb/t16636-2.html(24/6/2009).

[1] www.maeda-kougyou.com/ar/anz_paint.html(19/6/2009)

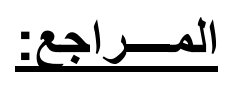

هالجهاز المركزي للإحصاء:"التقرير الإحصائى السنوي(2007م)"، الجمهورية اليمنية، صنعاء.

الصندوق الاجتماعي للتنمية بمدينة المكلا (2008م)، محافظة حضرموت، الجمهورية اليمنية.

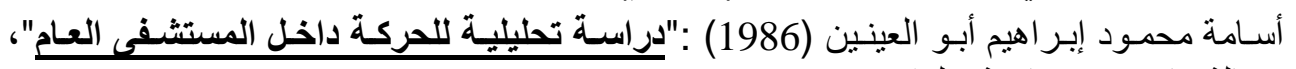

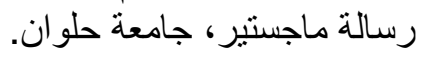

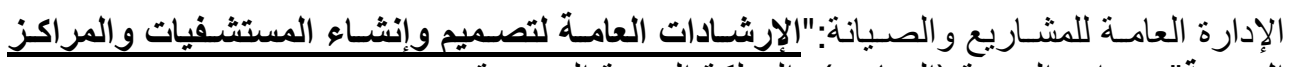

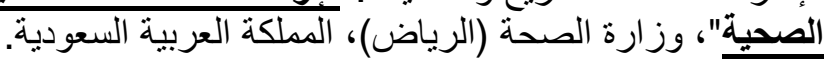

- Malkin ,Jain (1990):'Medical and Dental Space Planning', Van Nostrand Reinhold, New York, USA.

- The American Institute of Architects, Academy of Architectural for Health (dc2001 Edition):"Guidelines for Design and Construction of Hospital And Health Care Facilities", Washington, USA. 
- E.Todd Wheeler, FAIA(1964): 'Hospital Design and Functions, McGrawHill Book, New York.

مواقع الكثرونية:

- http://www.arab-eng.org/vb/t16636-2.html

- http://www.egymedica.com/ar_EgyMedica.html

- www.maeda-kougyou.com/ar/anz_paint.html 